\title{
Imaging Spectroscopy for the Detection, Assessment and Monitoring of Natural and Anthropogenic Hazards
}

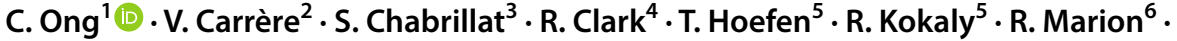 \\ C. R. Souza Filho ${ }^{7}$. G. Swayze ${ }^{5}$ D. R. Thompson ${ }^{8}$
}

Received: 15 January 2018 / Accepted: 23 February 2019 / Published online: 18 March 2019

(c) The Author(s) 2019

\begin{abstract}
Natural and anthropogenic hazards have the potential to impact all aspects of society including its economy and the environment. Diagnostic data to inform decision-making are critical for hazard management whether for emergency response, routine monitoring or assessments of potential risks. Imaging spectroscopy (IS) has unique contributions to make via the ability to provide some key quantitative diagnostic information. In this paper, we examine a selection of key case histories representing the state of the art to gain an insight into the achievements and perspectives in the use of visible to shortwave infrared IS for the detection, assessment and monitoring of a selection of significant natural and anthropogenic hazards. The selected key case studies examined provide compelling evidence for the use of the IS technology and its ability to contribute diagnostic information currently unattainable from operational spaceborne Earth observation systems. User requirements for the applications were also evaluated. The evaluation showed that the projected launch of spaceborne IS sensors in the near-, mid and long term future, together with the increasing availability, quality and moderate cost of off the shelf sensors, the possibilities to couple unmanned autonomous systems with miniaturized sensors, should be able to meet these requirements. The challenges and opportunities for the scientific community in the future when such data become available will then be ensuring consistency between data from different sensors, developing techniques to efficiently handle, process, integrate and deliver the large volumes of data, and most importantly translating the data to information that meets specific needs of the user community in a form that can be digested/understood by them. The latter is especially important to transforming the technology from a scientific to an operational tool. Additionally, the information must be independently validated using current trusted practices and uncertainties quantified before IS derived measurement can be integrated into operational monitoring services.
\end{abstract}

Keywords Hazards · Imaging spectroscopy $\cdot$ Hyperspectral $\cdot$ Acid mine drainage $\cdot$ Dust $\cdot$ Hydrocarbon $\cdot$ Atmospheric emissions $\cdot$ Aerosols $\cdot$ Asbestos $\cdot$ Swelling clay

Disclaimers: Any use of trade, product or firm names in this chapter is for descriptive purposes only and does not imply endorsement by the US Government.

C. Ong

cindy.ong@csiro.au

Extended author information available on the last page of the article 


\section{Introduction}

A hazard is broadly defined as a process, phenomenon or human activity that may cause loss of life, injury or other health impacts, property damage, social and economic disruption or environmental degradation (United Nations Office for Disaster Risk Reduction 2017). Hazards may be classified as active where the condition is certain to cause harm, or the hazards are classified as latent where they represent future threats. Most hazards are dormant with only a theoretical risk of harm. When the level of risk/threat and vulnerability elevates to cause the hazards to be severe and large scale, they are classified as disasters (Jha 2010).

Natural hazards are those that are associated with natural processes and phenomena including but not limited to wildland fires, dust storms, volcanic eruptions, hurricanes, floods, earthquakes, swelling clays (when exposed to excess water) and acid sulphate soils. Natural hazards have significant societal and environmental impacts. Anthropogenic hazards are those that are induced by human forces and encompass those that are both accidental and intentional in nature. Anthropogenic hazards can occur from activities such as non-renewable resource exploitation, industrial processing, agriculture, urban development, transportation, and shipping. Lastly, some hazards are classified as socio-natural, in that they are associated with a combination of natural and anthropogenic factors including environmental degradation and climate change.

Passive and active satellite Earth observations have been used for decades to inform decision-making on natural and anthropogenic hazards (Hong et al. 2007; Joyce et al. 2009; Lentile et al. 2006; Metternicht and Zinck 2003; Tralli et al. 2005) and are now generally accepted operational tools for this purpose. Until recently, imaging spectroscopy (IS), particularly from satellite platforms, has not been operationally available and hence is not yet as widely or operationally used. IS is defined as the simultaneous acquisition of spatially co-registered images in many spectrally contiguous bands $(>50)$, measured in calibrated radiance units, from a remotely operated platform (Schaepman et al. 2009; Goetz 2009). IS has unique contributions to make via its ability to provide quantitative diagnostic information to better inform assessments and monitor hazards and their related threats. In the last two decades, with the increasing availability of IS particularly in the visible (VIS) to shortwave infrared (SWIR) (400-2500 nm) range mainly from airborne platforms, some convincing studies have demonstrated its remarkable effectiveness (for acid drainage see Buzzi et al. 2016; Davies and Calvin 2017; Farrand 1997; Farrand and Harsanyi 1997; Fenstermaker and Miller 1994; Kemper and Sommer 2004; King et al. 1995; Kopačková 2014; Kruse et al. 1989; Lopez-Pamo et al. 1999; Ong and Cudahy 2014; Pearson et al. 1997; Peters et al. 1995; Shi et al. 2014a, b; Swayze et al. 1996, 2000; Rockwell et al. 2005; Zabcic et al. 2014; for fugitive dust see Clark et al. 2006; Chudnovsky et al. 2009, 2011; Ong et al. 2003a, b, c, 2008; Ong 2013; Pascucci et al. 2012; for hydrocarbon contamination see Beland et al. 2016; Clark et al. 2010; Khanna et al. 2013; Kokaly et al. 2013; Peterson et al. 2015; for atmospheric emissions see Bradley et al. 2011; Dennison et al. 2013; Deschamps et al. 2013; Franke et al. 2009; Frankenberg et al. 2016; Frassy et al. 2014; Krautwurst et al. 2017; Leifer et al. 2012; Marion et al. 2004; Roberts et al. 2010; Spinetti et al. 2008; Thompson et al. 2105b; Thorpe et al. 2012, 2013; and, for naturally occurring hazardous soils and rocks, see Bonifazi and Serranti 2016; Chabrillat et al. 2002, Chabrillat and Goetz 2006; Clark et al. 2001, 2003b; Marino et al. 2000; Massarelli et al. 2017; Swayze et al. 2004, 2009; Swayze and Kokaly 2016, and many others). 
In this paper, we examine a selection of significant anthropogenic and natural hazards and show, through some key case histories, how visible (VIS)- shortwave (SWIR) IS has been used to enhance understanding and improve decision-making and management of these challenges. Finally, we explore the limitations of current systems and requirements for future operational systems.

\section{Theory and Concepts}

Most of the studies conducted thus far on the use of IS for natural and anthropogenic hazards exploit the fact that the hazardous material (be it soil, water or air) has compositional characteristics that are spectrally distinct. In contrast, the surrounding non-hazardous material may have different or no diagnostic spectral features that can be used to distinguish it from the hazardous material. Therefore, the use of IS for hazards is essentially the use of spectroscopy for the detection and identification of materials be they solid, liquid or gas.

Spectroscopy deals with the interpretation, as a function of wavelength, of light reflected, emitted, transmitted or scattered, resulting from the interaction of electromagnetic radiation with matter (atoms and molecules). Absorption and scattering are the two main physical properties that can be used to identify and quantify constituents from both the surface and the atmosphere.

Figure 1 illustrates the driving mechanisms for spectral absorption features, the significance of the wavelength location and shape of spectral features for identification and quantification of the material of interest. As most of the key components of the anthropogenic hazards examined for this paper were characterized by their mineralogical composition, this figure is illustrated with two minerals. The principles described here are similarly applicable to other materials. In the ultraviolet (UV)-VIS wavelength range, the energy of a photon is used to excite electrons to a higher energy level (transition). The energy transitions for the electrons of each element are unique and are distinct from one another. For minerals, absorption features in the UV-VIS-nearinfrared (VNIR) spectral range are generally broad and caused by electronic transitions, crystal field effects and charge transfers that can be used to distinguish the observed material. For example, for the jarosite (an iron-bearing mineral) spectrum in Fig. 1, the electronic transitions and crystal field effects at wavelengths around 430, 550 and $900 \mathrm{~nm}$ allow for identification of materials containing iron $\left(\mathrm{Fe}^{+3}\right)$.

At longer wavelengths beyond the NIR towards the shortwave (SWIR) and long-wave infrared (LWIR), the energy of a photon produces changes within the atoms and molecules, more specifically vibrations of atomic or molecular bonds. As a result, the specific wavelengths of light are absorbed, resulting in narrow diagnostic absorption features that can be used to uniquely identify the observed material. Molecular vibrational features at wavelengths between 1000 and $2500 \mathrm{~nm}$ are diagnostic of materials containing anion groups, such as $\mathrm{Al}-\mathrm{OH}, \mathrm{Mg}-\mathrm{OH}, \mathrm{Fe}-\mathrm{OH}, \mathrm{Si}-\mathrm{OH}, \mathrm{CO}_{3}, \mathrm{NH}_{4}$ and $\mathrm{SO}_{4}$ as illustrated by the $\mathrm{Al}-\mathrm{OH}$ and $\mathrm{Fe}-\mathrm{OH}$ features in Fig. 1 diagnostic of alunite and jarosite, respectively. Often, the various diagnostic absorption features of materials (such as the crystal field and $\mathrm{Fe}-\mathrm{OH}$ of jarosite) are used in unison to interpret the spectrum, which explains why the complete VIS-SWIR is required. Small differences in the absorption band wavelength position and shape are correlated with both material composition and variability. 


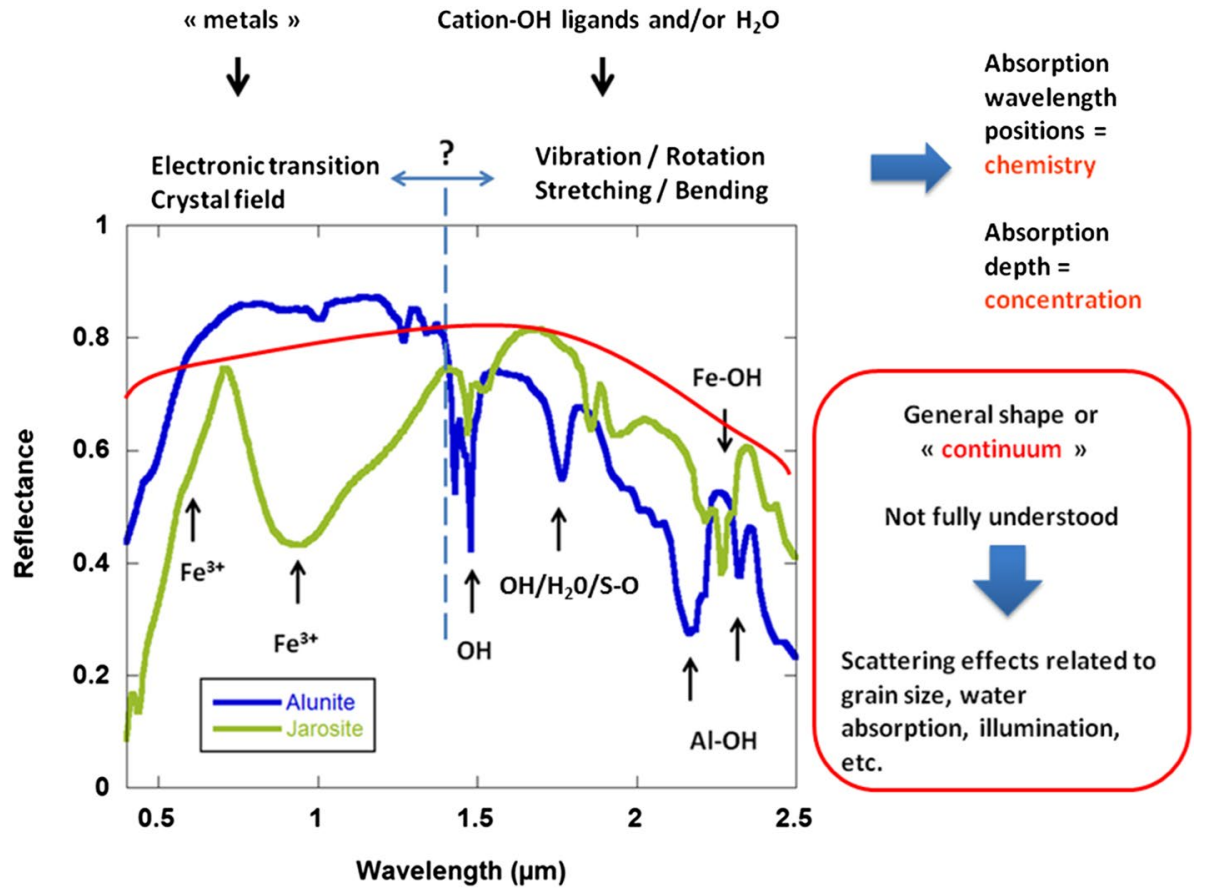

Fig. 1 Illustration of diagnostic spectral absorption features and the processes that cause them, and the relevance of the wavelength positions and shape for discriminating the material. The red line represents the hull or continuum of the spectrum

Additionally, absorption strength (or depth) is controlled by the optical properties, grain size and concentration of the chemical constituent (mineral, liquid or gas), according to Beer-Lambert's law (Swinehart 1962). The general shape of a reflectance spectrum (also called continuum) is mostly influenced by the physical properties of the medium. Photons can be reflected from grain surfaces or refracted through a particle and thus be scattered. The intensity of the scattering process is controlled by the size of the grains, their optical properties and the energy of the photons. The amount of light scattered and absorbed by a grain is dependent on grain size, more specifically on the surface-to-volume ratio. The larger the grain, the larger the internal path and the higher the probability for the photons to be absorbed. Conversely, the smaller the grain, the more the surfaces of reflection and the more the scattering. As a consequence, the reflectance decreases with increasing grain size. The shape of the continuum may also be due to larger absorption features such as the wing of the 2800-nm fundamental water absorption in the SWIR.

In addition to mineralogical compositions, the other key component used to characterize the hazards examined was gaseous constituents. Gases and aerosols also have diagnostic absorption or emission features in the VIS-SWIR from which their compositions can be distinguished, which are driven by electronic transitions in the UV-SWIR region and, by vibrational-rotational transitions in the VIS-SWIR. For example, $\mathrm{CH}_{4}$ has diagnostic absorption features around $1700 \mathrm{~nm}$, which is the first overtone of the C-H stretch fundamentals around $3400 \mathrm{~nm}$, and, has an additional diagnostic absorption feature at $2300 \mathrm{~nm}$ likely caused by multiple combinations and overtones (Clark et al. 2009) (see spectrum of $\mathrm{CH}_{4}$ in Fig. 2). 


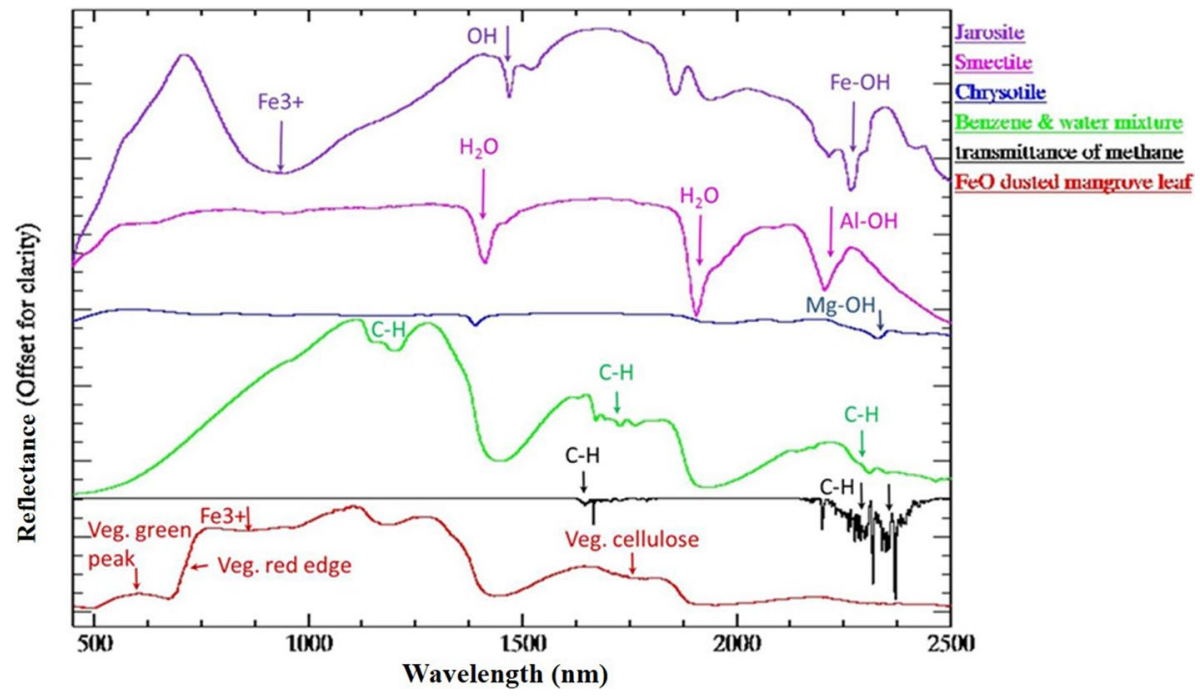

Fig. 2 Spectra of a selection of key minerals, organic compounds and hydrocarbons related to natural and anthropogenic hazards (sourced from a combination of Kokaly et al. 2017 and Ong 2013). Specifically, the spectra shown are of: jarosite, a key secondary mineral resulting from acid mine drainage (AMD); smectite, a mineral used to identify swelling clay; chrysotile, a mineral with asbestiform crystal habits; benzene and water mixture; methane, the main composition of natural gas and an iron oxide-dusted mangrove leaf

When spectral data are acquired remotely such as the case of IS, the signal recorded by IS includes the atmospheric column between the sensor and the ground surface, which must be accounted for and removed, particularly for spatially varying constituents such as water vapour. Therefore, investigators now routinely estimate atmospheric gaseous constituents based on their absorption features, via a process called atmospheric correction as an intermediate step before the retrieval of surface reflectance spectra (Frouin et al. 1990; Gao and Goetz 1990; Kaufman and Gao 1992; Carrère and Conel 1993; Schläpfer et al. 1998; Qu and Kindel 2003; Cairns et al. 2003; Thompson et al. 2015). The retrieval of gaseous constituents for gaseous hazard monitoring is analogous. In addition, scattering by air molecules (Rayleigh and Raman scattering), scattering and absorption by aerosol and cloud particles (Mie scattering), refraction due to the density gradient in the atmosphere and surface reflection attenuate these absorption or emission features of gaseous compositions and must be accounted for (Gottwald et al. 2006).

In summary, spectroscopy provides unique diagnostic capabilities for identifying and quantifying solid, liquid and gaseous materials giving IS these added diagnostic capabilities in addition to providing locational and spatial context. The theory, principles and concepts of spectroscopy of rocks, gases and other materials are comprehensively described by Farmer (1974), Burns (1993), Clark (1999), Hunt and Ashley (1979), Hunt (1977, 1980), Gottwald et al. (2006), and others. In addition, the theoretical background concepts on gases are described in more detail in Thompson et al. (2019) (this issue) and Chabrillat et al. (2019) (this issue) provide further supplementary details specifically on soils. 


\section{Applications to Anthropogenic and Natural Hazards}

The use of Earth observation for natural and anthropogenic hazards have now been comprehensively proven and is generally accepted as an operational tool (Hong et al. 2007; Joyce et al. 2009; Lentile et al. 2006; Metternicht and Zinck 2003; Tralli et al. 2005). The advantages of Earth observation include the ability to provide non-contact, timely, temporal and spatial context useful for assessments of risks, characterization of hazardous events and monitoring post-event remediation efforts. IS, similarly, has these capabilities, but IS is augmented with unique diagnostic capabilities, allowing more accurate identification and quantification of risks, to improve targetting of emergency responses and, enhanced the understanding of the progress of remediation efforts.

In this section, we aim to show the augmented diagnostic capabilities of IS by emphasizing selected case histories that demonstrate the added values of IS. Additionally, as much as possible we focus on case histories where the full VIS-SWIR wavelength ranges are critical for retrieving accurate and quantitative information. This was particularly done to understand the value of future spaceborne IS which will be operating in those ranges.

Finally, we provide a synopsis on the case histories examined, describing the value of the diagnostic capabilities of IS, the spatial requirements, the status of the processing and analysis methods and the findings in the context of their benefit for improving identification and quantification of risks, improving targeting of emergency responses and enhancing the understanding of the progress of remediation efforts.

\subsection{Acid Drainage}

The application of IS in acid mine drainage (AMD) management is one of the most welldocumented uses of IS for studying anthropogenic hazards in the last two decades (see Table 1). AMD is an anthropogenic hazard that has been recognized as one of the most significant environmental challenges of the mineral industry (Akcil and Koldas 2006; Harries 1997). AMD is commonly defined as water seepage, with a $\mathrm{pH}$ less than 5 , originating from a tailings dam, a waste rock pile or exposed sulfide-rich rock (Shaw et al. 1998). In most cases, acidic seepage comes from the oxidation of iron sulphide or pyrite $\left(\mathrm{FeS}_{2}\right)$. The oxidation process may be induced by a variety of geochemical agents but is usually associated with Fe-oxidizing thiobacilli organisms, the most common of which is Thiobacillus ferrooxidans, at pH values below 4.5 (Bigham et al. 1996).

The use of VIS-SWIR IS for characterizing AMD is advantageous because many of the secondary minerals formed by the oxidation of pyrite and other iron sulfide minerals in mine waste and mineralized rocks have diagnostic spectral features detectable in the VIS-SWIR range. Specifically, many of the secondary minerals such as copiapite, jarosite, schwertmannite, ferrihydrite, goethite and haematite are iron-rich and show spectrally diagnostic features around 430, 550 and $900 \mathrm{~nm}$ related to ferric iron crystal field transition (see jarosite spectrum in Fig. 2), and many are hydroxyl-bearing, showing diagnostic absorption features around $2265 \mathrm{~nm}$ related to $\mathrm{Fe}-\mathrm{O}-\mathrm{H}$ vibrational mode as shown in the jarosite spectrum in Fig. 2 and therefore having diagnostic spectral reflectance signatures (Cloutis et al. 2006; Swayze et al. 2000; Crowley et al. 2003).

The speciations of these secondary minerals are controlled by $\mathrm{pH}$, the degree of oxidation, moisture content and solution composition (Swayze et al. 2000). A prolonged period of drying of these acidic waters can produce a suite of efflorescent salts (many of which 


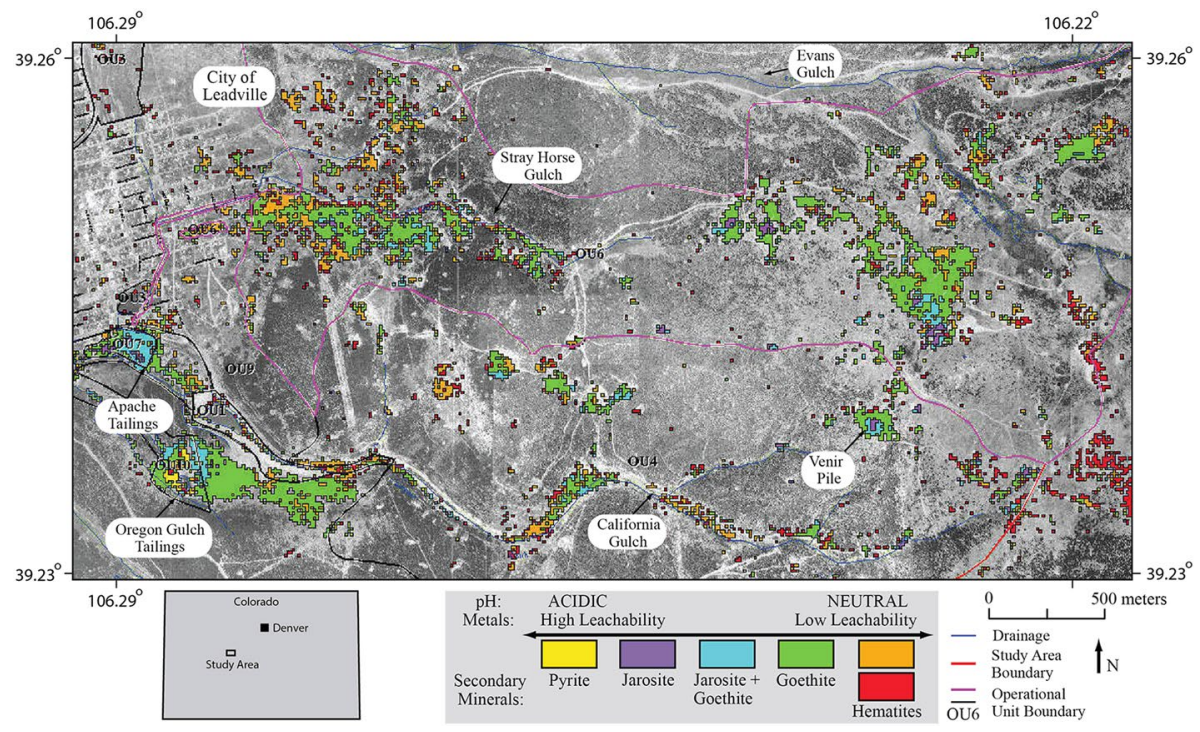

Fig. 3 Secondary minerals related to the AMD process in the Leadville Mining District, Colorado, USA, mapped using IS data acquired using the airborne AVIRIS-C sensor. An idealized bull's eye model of spectrally detectable secondary mineral zones and their relation to acidity and metal leachability is shown to ease "translation" of the maps into parameters such as $\mathrm{pH}$ levels that are usually better known to environmental practitioners (adapted from Swayze et al. 2000)

also have spectrally diagnostic features in the VIS-SWIR range) and when dissolved can rapidly decrease the $\mathrm{pH}$ of acid waters and can result in short-term catastrophic effects on metal loadings and harm aquatic ecosystems (Hammarstrom et al. 2005). The leachate acidity is also capable of releasing heavy metals such as $\mathrm{As}, \mathrm{Pb}, \mathrm{Cu}, \mathrm{Co}, \mathrm{Zn}, \mathrm{Cd}$ which are substituted with iron in the secondary minerals. AMD, therefore, can adversely impact the quality of drinking water and the health of riparian ecosystems. The task of identifying the sources, measuring the extent and determining the severity of AMD with traditional field methods can be costly and time-consuming.

Pioneering work by Swayze et al. (1996, 2000) at a test site near Leadville, Colorado, USA, in the district historically mined for gold, silver, lead and zinc since 1859 (Emmons et al. 1927) demonstrated that spectrally dominant iron minerals (pyrite, jarosite, a jarosite and goethite mixture, and haematite) exposed on the surface of the waste rock and tailings piles at Leadville can be identified and mapped using the $\mathrm{Fe}-\mathrm{O}-\mathrm{H}$ and $\mathrm{Fe}^{3+}$ diagnostic spectral absorption features related to those secondary minerals (Fig. 2), used from Airborne Visible/Infrared Imaging Spectrometer Classic (AVIRIS-C) (Vane et al. 1993) imaging spectrometer acquired from an airborne platform (Fig. 3).

In the Leadville study, secondary minerals resulting from AMD were mapped using Tetracorder, a spectral shape-matching system (Clark et al. 2003a) applied to atmospherically corrected and calibrated AVIRIS-C data. Tetracorder is a modified least squares shape-matching algorithm that compares the continuum-removed (Clark and Roush 1984) absorption features of spectra of a comprehensive reference library to those of an observed spectrum (in this case the IS data). The continuum removal for each spectrum in the reference library spectra is tuned to the wavelength region around key diagnostic absorption features. Before comparison of each observed spectrum, it is first normalized against its 
continuum around the same wavelength region of the diagnostic absorption feature of the reference library spectrum and then scaled by a multiplicative constant so that its depth matches that of the corresponding reference absorption feature. Least squares correlation coefficients are then calculated and weighted according to the area under the curve and/or optional user-defined weights. Sets of absorption features for specific materials are compared based on a prescribed set of rules. An identification is then issued based on the application of these rules to the calculated values.

Validation of these mineral maps with a comprehensive suite of ground-based spectral measurements analysed using Tetracorder and independently cross-validated with soil samples collected from the site which were laboratory-analysed for leachate $\mathrm{pH}$, leachate-specific conductance, bulk metal composition and metal leachability (see Swayze et al. 2000 for details) indicated that, the correlation between the AVIRIS-C-derived map and the ground traverse was very good except near man-made structures with rusted metal roofs and walls, which have a goethite spectral signature. The leachate chemical analyses indicate excellent correlation between mine waste $\mathrm{pH}$ and spectral zones mapped using IS, and the leachate trace metal concentrations generally showed a good correlation to the spectral mineral zones with metal leachability in the goethite zone with a small fraction of that in the other spectral zones (except for $\mathrm{Mn}$ ). In fact, leachate concentrations of $\mathrm{Pb}, \mathrm{Cu}, \mathrm{As}$ and Co vary over three orders of magnitude across the spectral zones. This is significant because it indicates that the mineralogy in the spectral zones exerts a powerful control on metal leachability (e.g., the susceptibility of metals to leach into surface run-off) and hence the mapping of these minerals will be a good surrogate for leachability.

In summary, the maps produced from the Leadville study provided identification, location, spatial distribution and quantification of risks contributing towards improved targeting of remediation efforts which would otherwise be time-consuming and costly to map with traditional methods. In this regard, IS data could represent considerable savings in environmental remediation efforts.

Following the Leadville work, many other similar studies were conducted demonstrating the use of imaging spectrometers for mapping secondary minerals related to acid drainage (Kruse et al. 1989; Fenstermaker and Miller 1994; King et al. 1995; Peters et al. 1995; Farrand 1997; Farrand and Harsanyi 1997; Lopez-Pamo et al. 1999; Rockwell et al. 2005; Pearson et al. 1997; Kemper and Sommer 2004 and many others). Of particular interest, are the studies conducted by Zabcic et al. (2014) and Buzzi et al. (2016) who carried out the mapping of efflorescent salts, many of which have spectrally diagnostic features. For example, malenterite has a broad double crystal field transition absorption feature at 892 and $1150 \mathrm{~nm}$ related to ferrous iron and a smaller absorption feature at $434 \mathrm{~nm}$ related to $\mathrm{Fe}^{3+}-\mathrm{O}$ charge transfer feature (Crowley et al. 2003). These efflorescent salts, which are often difficult to detect remotely because of their small size, were detected using HyMap (Cocks et al. 1998) airborne hyperspectral data acquired at the Sotiel Migollas Mine in the Iberian Pyrite Belt, Spain. The detection followed several years of drought allowing large spatial distributions of these salts at the tailings holding ponds and to a lesser extent on riverbeds to be formed. Here, the mapping of these salts by Zabcic et al. (2014) was done using a combination of the spatial-spectral endmember extraction (SSEE) algorithm (Rogge et al. 2006) for extracting spectral endmembers and iterative linear spectral unmixing analysis (ISMA) (Rogge et al. 2006) to derive the mineral maps, and, by Buzzi et al. (2016) using the Spectral Angle Mapper (SAM) (Kruse and Dwyer 1993) to perform the mineral mapping. The ability to detect these salts is significant as these salts are one of the most potent sources of metals, providing a ready source of acids and metals (Alpers et al. 
1994; Plumlee et al. 1999). Specifically for the Sotiel Migollas Mine, the maps showing the abundance of these efflorescent salts is potentially useful for estimating the concentration of heavy metals and other hazardous metals that could be liberated and hence infer the risks of this abandoned mine where the infrastructure is thousands of years old, where an accidental spill or breach of the tailings pond following the next heavy rainfall event would have significant implications as in the case of the Aznalcollar accident (Achterberg et al. 1999; van Geen and Chase 1998). In fact, the use of IS for determining heavy metal loads was demonstrated by Kemper and Sommer (2004) following the Aznalcollar incident providing useful data for understanding the distribution and severity of the hazard and contributed towards better targeting of the cleanup process.

Although mapping of AMD conditions is crucial for characterizing AMD hazards, assessing its risks and targeting remediation work, monitoring is equally essential after remediation work commences. This monitoring aspect is demonstrated by Zabcic et al. (2014), Ong and Cudahy (2014) and Buzzi et al. (2016) using multi-temporal airborne IS data. By exploiting the relation between the minerals generated as a result of AMD and pH, Zabcic et al. (2014) and Ong and Cudahy (2014) extended the mapping of AMD mineral from IS to $\mathrm{pH}$ maps using Partial Least Squares (PLS) (Haaland and Thomas 1988). Such translated maps are useful for downstream users such as on-site environmental practitioners to understand the temporal evolution of the acid-producing material and to target and assess the effectiveness of remediation efforts.

Acid sulphate soil (ASS) is a socio-natural hazard where acidic soils or sediments that contain iron sulphides, mainly pyrite, and sulphuric acid are exposed either via natural or anthropogenic activities such as urban development. ASS is widely distributed around the world and has raised environmental concerns because of its the soil's capability to produce strong acidity and consequent trace metal release. The mechanism and oxidation process is similar to AMD, hence the methods used for AMD are equally relevant. As it is challenging to detect the occurrence and severity of ASS by conventional methods, which include time-consuming intensive field surveys followed by chemical measurements, mapping the location and severity of ASS from IS is an attractive prospect. Studies were conducted by Shi et al. (2014a, b), which showed that secondary minerals and associated $\mathrm{pH}$ related to ASS surrounding an estuary in Western Australia could be mapped using similar spectral feature fitting and PLS analysis methods as the AMD studies described above. Such maps help to improve targeting of remediation efforts and inform land-use planning. However, ASS generally is spatially small, posing cost challenges for current IS.

In terms of understanding the capabilities for future spaceborne IS, Davies and Calvin (2017) conducted a study to simulate the ability of future spaceborne IS and found that identification of key minerals related to AMD were possible at all spatial resolutions $(2-60 \mathrm{~m})$ albeit the finest spatial resolution images provided the best result with the most endmembers with more accurate spatial boundaries, and the lowest spatial resolution lost the ability to identify smaller features. Specifically, the areas mapped were reduced by one half when the spatial resolution was reduced to $15 \mathrm{~m}$, but from 15 to $30 \mathrm{~m}$, no further reduction in the area mapped was seen. Further, they found that near-future spaceborne IS which will predominantly be at a spatial resolution of $30 \mathrm{~m}$, will be most relevant to identifying potentially hazardous AMD that cover large areas of at least $75 \mathrm{~m}$ in width. 


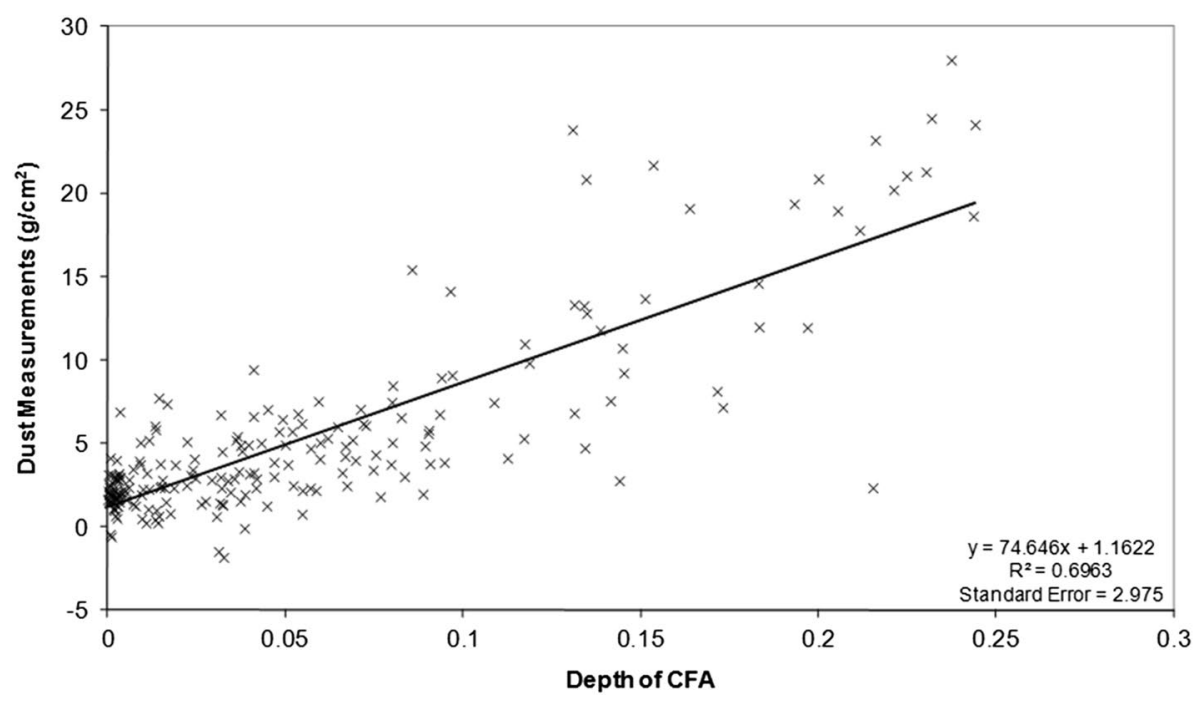

Fig. 4 Scatterplot of the crystal field absorption (CFA) feature near $900 \mathrm{~nm}$ for ferric iron oxide (x) and the mass per unit area of dust on the leaves (y) from which an empirical line relation was developed to estimate iron oxide dust quantities using airborne IS data (sourced from Ong 2013). $\mathrm{R}^{2}$, coefficient of determination

\subsection{Fugitive Dust}

The detection and diagnosis of hazardous fugitive dust, whether naturally occurring or anthropogenic, is based on spectroscopic principles where spectrally diagnostic features of the dust deposited on surfaces of leaves, soils or other background materials are used as markers/fingerprints for detecting the distribution and quantification of the concentration. Also, the underlying surfaces may have spectrally diagnostic features that may be used to identify the material where the dust is deposited. An example of this is the case of the spectrum of an iron oxide-dusted leaf in Fig. 2, where the ferric iron crystal field absorption (CFA) feature around $900 \mathrm{~nm}$ is evident together with features related to the chlorophyll vegetation such as the green peak at $550 \mathrm{~nm}$, the red edge between 650 and $750 \mathrm{~nm}$ (Filella and Peñuelas 1994 and references therein) and cellulose feature around $1700 \mathrm{~nm}$.

Although the use of IS to manage fugitive dust is not as comprehensively studied as AMD, Ong et al. (2003a, b, c), Ong et al. (2008) and Ong (2013) undertook an extensive study related to mineral resource development and the associated operations at the Port Hedland handling facility in Western Australia to better understand the impacts of fugitive dust originating from the handling of iron ore on the surrounding mangrove ecosystem. The method employed relied on an extensive calibration dataset of field samples to correlate the ferric iron oxide CFA feature around $900 \mathrm{~nm}$ to laboratory measurements of surficial dust quantities. Specifically, an empirical line relation between the continuumremoved 900-nm CFA depth and dust concentrations (see Fig. 4) was developed that was then applied to atmospherically corrected and continuum-removed airborne HyMap data collected over a 10-year period.

The resulting dust maps shown in Fig. 5 demonstrate that it is possible to positively identify the source of the fugitive dust and quantitatively identify, measure, map and monitor the spatial distribution of fugitive iron oxide dust through time. The ability to 

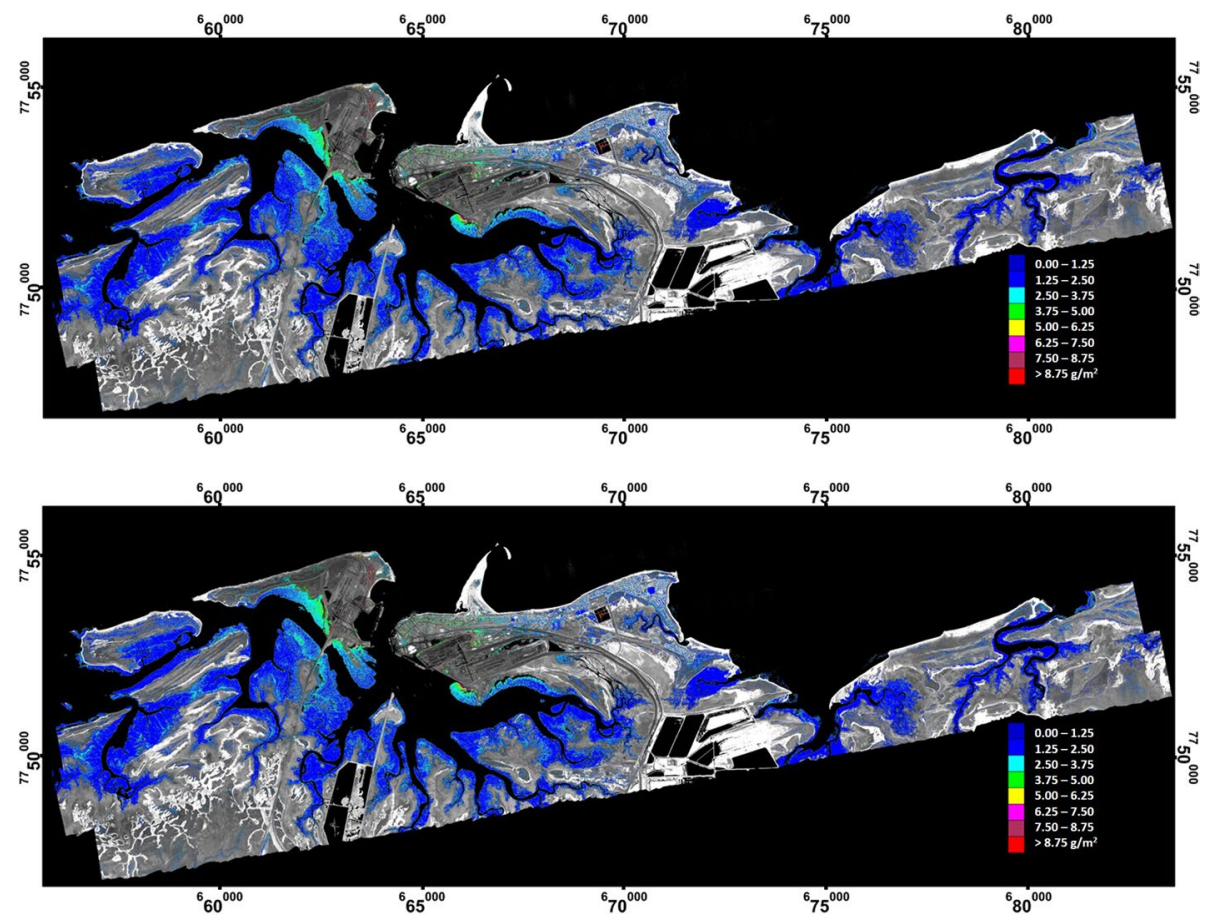

Fig. 5 Maps of ferric iron oxide dust levels on mangroves and other vegetation surrounding Port Hedland harbour, Western Australia, generated from remotely sensed IS data acquired on 20 October 2002 (top) and 24 August 2006 (bottom). The color coding is such that cool colors (starting with dark blue) denote low fugitive dust levels and hot colors (ending with red) denote high fugitive dust levels. The dust measurements are in units of $\mathrm{g} / \mathrm{m}^{2}$. Image sourced from Ong et al. (2008) and Ong (2013)

provide identification and quantification is important in this case as the mining company is obliged via a ministerial agreement to monitor their impact. Additionally, the spectral-derived maps provided new insights into the spatial distribution of fugitive dust across the landscape where it was not possible with previous methods, which, had acquired measurements at a few discrete points and did not allow for rapid identification of the composition of the dust. The spectral-derived maps generated from the Ong (2013) study were comprehensively validated paving the way for the method to potentially be used operationally, especially after the launch of future spaceborne IS sensors such as Environmental Mapping and Analysis Program (EnMAP, Guanter et al. 2015), Hyperspectral Imager Suite (HISUI, Matsunaga et al. 2018), Surface Biology and Geology (SBG, Green 2018, previously Hyperspectral InfraRed Imager (HyspIRI, Lee et al. 2015), Hyperspectral Imaging Mission for the Environment (CHIME, Nieke and Rast 2018) and Hyperspectral Precursor of the Application Mission (Loizzo et al. 2018). Importantly, the Ong (2013) study was undertaken to quantify the uncertainties in the dust products generated using the method. Quantifying these uncertainties is important when such measurements are used to meet regulatory requirements. For example, 
it was determined that the wavelength miscalibration of up to $2.1 \mathrm{~nm}$ could potentially increase the uncertainties up to $34 \%$ in the determination of fugitive dust levels.

Further to this work, Ong et al. (2008) and Pascucci et al. (2012) provide supporting evidence of the potential to map and characterize other fugitive dusts based on the spectrally diagnostic features of the hazardous material at other mining operations.

Often large amounts of fugitive dust can be generated as a result of accidental spills or human malice. In some cases, the dust can be hazardous. Therefore, the deployment of IS for the task of remotely and rapidly detecting and locating the deposition of fugitive dust after such a hazardous event presents an important tool for emergency responders and those involved in the clean-up especially where there is a safety concern for those undertaking the clean-up process. IS from AVIRIS-C sensor was deployed for such an application where potentially hazardous dust was discriminated following the 11 September 2001 World Trade Centre (WTC) attack (Clark et al. 2006). Specifically, the AVIRIS-C data were used to map the abundance and extent of dust and debris resulting from the collapse of the WTC using Tetracorder. Of immediate concern was the potential presence of asbestos-bearing materials in the dust, and hence the data were used to determine the presence and distribution of asbestos materials using the $\mathrm{Mg}-\mathrm{O}-\mathrm{H}$ spectral absorption feature present in chrysotile (Figs. 2, 6). Although spectroscopy is only able to measure minerals related to asbestos and will not discriminate between asbestiform or non-asbestiform particles, the AVIRIS-C data were able to identify pockets (or small clusters of pixels) of serpentine, indicating potential asbestos levels of a few per cent, up to 10 and $20 \%$. Such data were valuable as guidance towards determining the risks to those involved in the clean-up operations.

Dust storms are natural atmospheric events that are typically associated with deserts, and they are known to cause significant impacts on the physical environment and human health (Goudie and Middleton 2006). Often dust storms carry mineral dust from eroded exposed soil surfaces.

Chudnovsky et al. $(2009,2011)$ employed spectral matching to known mineralogical spectral features (Duckworth 2004) and SAM (Kruse and Dwyer 1993) using spaceborne IS data acquired by National Aeronautics and Space Administration (NASA) EO-1 Hyperion sensor to map the mineral composition of the dust at the Bodélé Depression of Northern Chad, considered to be one of the world's largest sources of atmospheric mineral dust. In the Chudnovsky et al. (2009) case study, they demonstrated that it was possible to detect key minerals from suspended dust particles from the remotely sensed spectral data. As the composition of the deposited dust can have varying impacts on the receptor environment (Jickells et al. 2005; Westrich et al. 2016), the ability to determine the composition of the dust is important for quantifying their impacts and predicting their associated risks. An extension of the case study (Chudnovsky et al. 2011) indicated that IS data can be used to map the distribution and composition of the dust via their mineralogical features, which in turn has the potential to be used to track the transportation routes of the dust. As this case study was conducted at similar spatial resolutions as future global and temporal spaceborne IS missions such as the SBG mission (Green 2018; Lee et al. 2015), the next-generation spaceborne IS missions would make such applications viable allowing a better understanding of dust on climate radiative forces. 


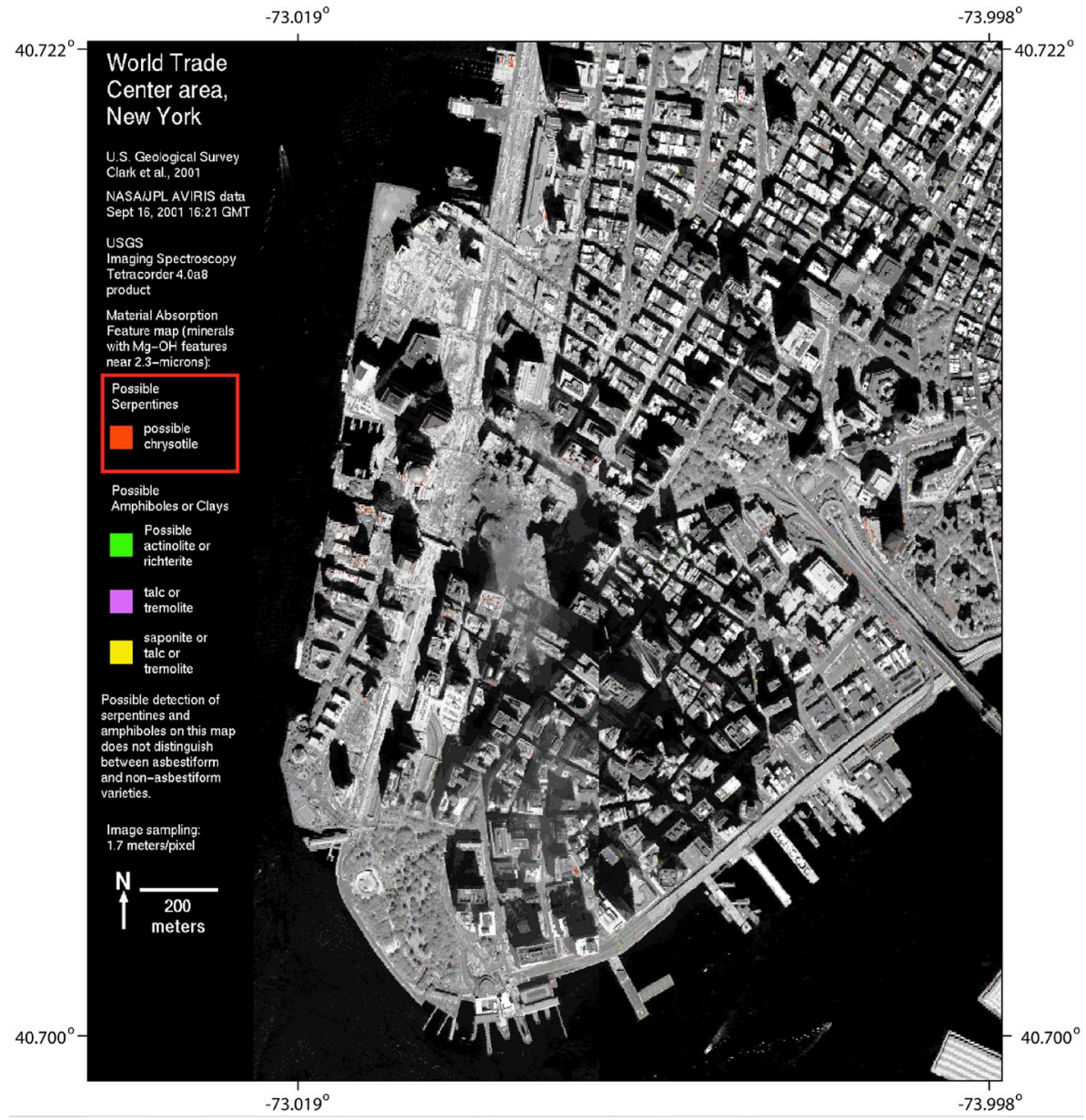

Fig. 6 Serpentine and amphibole minerals map of the lower Manhattan area, New York City, New York, USA. Image sourced from Clark et al. (2006)

\subsection{Hydrocarbon Contamination in Aquatic and Terrestrial Ecosystems}

An oil spill is oil, discharged accidentally or intentionally, that floats on the surface of water bodies as a discrete mass and is carried by the wind, currents and tides (United Nations Statistical Division 2017). The term oil spill usually refers to marine oil spills, where oil is released into the ocean or coastal waters, but spills may also occur on land. The largest oil spill in the US history occurred in the Gulf of Mexico on 20 April 2010, when an explosion on the Deepwater Horizon (DWH) offshore drilling rig released $780,000 \mathrm{~m}^{3}$ of crude oil into the Gulf before being capped on 15 July 2010 (Lehr et al. 2010).

The detection of oil spills, whether manifested on the ground or surfaces of rivers, lakes or oceans, from IS depends on the presence of diagnostic hydrocarbon spectral absorptions centered near 1200, 1700 and $2300 \mathrm{~nm}$ which arise from overtones and 
combinations of the fundamental absorptions of $\mathrm{C}-\mathrm{H}$ bonds (see the green-coloured spectrum of benzene and water mixture in Fig. 2).

During the DWH disaster, Clark et al. (2010) and Leifer et al. (2012) used a combination of airborne AVIRIS-C and multi-spectral Moderate Resolution Imaging Spectroradiometer (MODIS, Salomonson et al. 1989) data to estimate the spatial distribution and thickness of the oil spill on the ocean. Airborne IS data acquired on 17 May 2010 for approximately $30 \%$ of the core spill area were used to estimate the composition and thickness of the oil based on diagnostic hydrocarbon spectral features. Specifically, the AVIRIS-C data were processed with Tetracorder using 22 reference spectra of laboratory-constructed emulsions measured at oil thicknesses ranging from 0.025 to $28 \mathrm{~mm}$. Using these spectral-derived maps, the oil volumes within the top few millimeters of the ocean surface were estimated to be 19,000 (conservative) to 34,000 (aggressive) barrels of oil (Clark et al. 2010). The conservative and aggressive volume estimates are based on choosing either $2 \mathrm{~mm}$ (conservative) or $4 \mathrm{~mm}$ (aggressive) for AVIRIS-C spectra of sea surface emulsions that spectrally resemble similar-looking reference emulsions with those thicknesses.

As the AVIRIS-C data did not cover the entire extent of the oil spill, MODIS data were used to define the spatial boundaries and internal structure of the oil spill to extrapolate the estimation of the oil thickness to the larger spatial distribution of the oil spill. If the core spill areas not covered by AVIRIS-C contained similar amounts of oil and water-inoil emulsions, then extrapolation to the entire core spill area defined by the MODIS image indicated a minimum of 66,000-120,000 barrels of oil was floating on the surface (Clark et al. 2010). These surface volumes form the basis of the flow rate estimation (Labson et al. 2010) contributing to the clean-up process. However, these were conservative estimates as the calculation was made assuming thick surface oil and did not include oil in sheens, oil under the surface, oil washed onto land, or oil burned, evaporated, or bio-degraded. Indeed, field observations of the oil emulsions indicated that the thickness of oil could sometimes exceed $20 \mathrm{~mm}$. If this larger thickness was used to estimate the volume of oil, the estimation could potentially be as high as 150,000 barrels within the AVIRIS-C coverage. If this volume was extrapolated to the entire spill estimated by MODIS, the estimated volume for the core spill would be approximately 500,000 barrels of thick oil remaining on the ocean surface.

In addition to the oil on the surface of the ocean, the DWH oil spill caused oil to be washed onto approximately $796 \mathrm{~km}$ of shoreline comprised of intertidal marshes, disproportionally impacting salt marshes along the coastline of Louisiana, the USA (Michel et al. 2013). Using IS to understand the status and progress of rehabilitation of the impacted area was the subject of several studies.

Kokaly et al. (2013) applied spectral feature analysis to the AVIRIS-C data collected during and after the DWH oil spill to delineate the distribution of oil-damaged canopies in the marshes of Barataria Bay, Louisiana. Spectral feature analysis based on Material Identification and Characterization Algorithm (MICA), a shape-matching algorithm (Kokaly 2011), was used to compare the AVIRIS-C data to reference spectra of oiled marsh collected by the researchers during field surveys. The spectra fitting relied on both the 1700 and $2300 \mathrm{~nm} \mathrm{C-H}$ absorption features. A composite map of oiled areas at 3.5-m grid spacing (Fig. 7), accumulated over three dates, was found to be $93.4 \%$ accurate in detecting oiled shorelines.

Similarly, Peterson et al. (2015) applied multiple endmember spectral mixture analysis (MESMA) (Franke et al. 2009) to the same AVIRIS-C data for Barataria Bay to detect oil on the coastal marsh. Peterson et al. (2015) were able to obtain accuracies ranging 


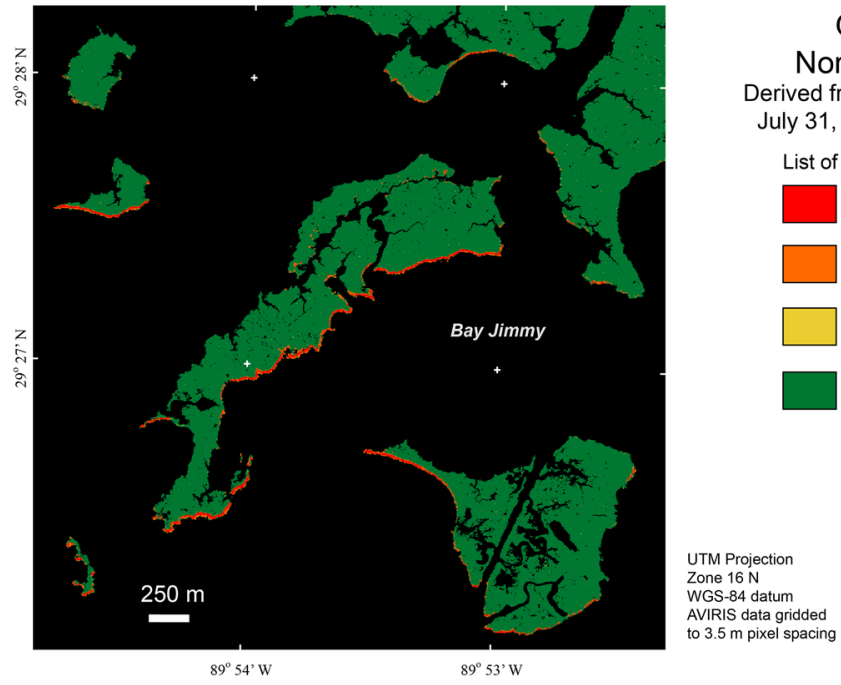

Oiled Marsh Map

Northern Barataria Bay

Derived from 2010 AVIRIS data collected uly 31 , September 14 , and October 4

List of Material Classes

Oiled marsh - Highest Probability Persistent and spatially contiguous

Oiled marsh - High Probability Persistent or spatially contiguous

Oiled marsh - Lower Probability Not persistent and not contiguous

Vegetation No detection

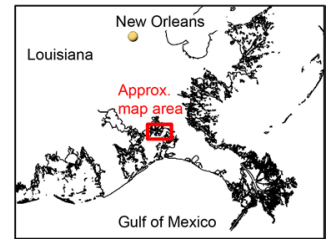

Fig. 7 Hydrocarbon contamination detected in AVIRIS-C data for the Deepwater Horizon oil spill in a portion of Barataria Bay, Louisiana, the USA. Figure adapted from Kokaly et al. (2013)

from 87.5 to $93.3 \%$ by using a nine-band subset emphasizing the hydrocarbon absorption regions.

AVIRIS-C data collected during the DWH oil spill and 1 year afterwards (2011) were used by Khanna et al. (2013) to show that vegetation stress, measured spectrally using the chlorophyll spectral absorption feature as indicated in Fig. 2, was restricted to the tidal zone extending $14 \mathrm{~m}$ inland from the shoreline in September 2010. The stress indices used showed that the highest values were located on pixels next to the shoreline and decreased with distance inland from the shore. The later imagery acquired in 2011 indicated that the stress index values were no longer correlated with proximity to oil, suggesting that the marsh on the Barataria Bay was on its way to recovery. One year after the oil spill, the data indicated that areas denuded of vegetation experienced varying degrees of revegetation and that recovery of plants was poorest in the first three pixels $(\sim 11 \mathrm{~m})$ adjacent to the shoreline.

Beland et al. (2016) evaluated changes in dominant species cover from 2010 to 2012 for oiled and non-oiled shorelines. They used field-referenced image endmembers and canonical discriminant analysis to classify 21 AVIRIS-C images acquired during the autumns of 2010, 2011 and 2012. Marshes that were heavily contaminated with oil exhibited variable responses from 2010 to 2012. Some marsh area was converted to open water along oiled and non-oiled shorelines that were similarly situated in the landscape. Marsh loss along oil-contaminated shorelines was double that of non-oiled shorelines. Analysis of dominant species showed that only Spartina alterniflora-dominated marshes were extensively degraded, losing $15 \%\left(354,604 \mathrm{~m}^{2}\right)$ cover in oiled shoreline zones, suggesting that $S$. alterniflora marshes may have been more vulnerable to shoreline erosion following hydrocarbon stress, due to their landscape position.

This case study from DWH demonstrated the use of IS not only for locating the oil spill but for identifying the different oil chemistries, including its weathering state and thickness. The provision of such diagnostic data is potentially beneficial for directing recovery efforts to areas where they are most effective. Also, IS data were demonstrated to be 
sufficient for identifying hydrocarbon contamination on marshes, and multi-temporal IS data were found to be effective for monitoring the impact and the recovery process of the vegetation.

\subsection{Atmospheric Emissions}

Atmospheric emission is a global issue projected by the Organization for Economic Cooperation and Development (OECD) to cause 6 and 9 million premature deaths in 2060 at the cost of USD18-25 trillion (OECD 2016). Much of this relates to air quality issues such as particulates and aerosols, especially in non-OECD (low income, low human development index, less developed) countries. However, in first-world nations, the greatest atmospheric emission issues by far are those that affect the climate-which in turn relates to modern society's heavy reliance on energy and the use of fossil fuels resulting in increased levels of greenhouse gases (OECD 2016). Studies demonstrating the use of IS for the detection of atmospheric gas relied on the fact that the atmospheric gas hazard was either spectrally distinct or was sufficiently enhanced from ambient conditions where the gas was a composition of ambient air. The former may be the case for industrial gases such as hexasulphur $\left(\mathrm{S}_{6}\right)$, while the latter may be the case with fugitive methane $\left(\mathrm{CH}_{4}\right)$ emissions from a coal mine or oil production equipment (see transmittance spectrum of methane in Fig. 2).

A long history of sounding ${ }^{1}$ missions has measured the atmosphere using absorption of reflected solar light (Rodgers 2000). Such instruments typically have coarse (>500 m) spatial resolution. In contrast, IS investigations have historically focused on higher spatial resolution mapping of Earth's surface at resolutions of 30-100 m (Schaepman et al. 2009). However, the VIS-SWIR region observes vibrational transitions by trace gases such as $\mathrm{CH}_{4}$ and $\mathrm{CO}_{2}$ and hence IS can be used to map these gases via the diagnostic atmospheric spectral features. The use of solar energy precluded the need for a scene temperature contrast, making the detection strength a predictable function of known illumination and simplifying quantitative analysis. Indeed, investigators routinely estimate atmospheric gas absorption as an intermediate step in atmospheric correction. More recently, advances in instruments and algorithms have made imaging of atmospheric composition a subject of study in its own right. IS has increasingly been deployed to image local atmospheric anomalies such as pollutants, aerosols and enhancements of trace gases such as carbon dioxide $\left(\mathrm{CO}_{2}\right)$, methane $\left(\mathrm{CH}_{4}\right)$ and sulphur dioxide $\left(\mathrm{SO}_{2}\right)$. While trace gas characterization has more often used sounding spectrometers (Gerilowski et al. 2011) or in situ airborne sensors (Conley et al. 2016), imaging spectrometers bring unique capabilities. IS can survey wide areas, detecting spatially small sources that had not been identified previously. The higher spatial resolutions afforded by IS provide the ability to improve localization and attribution to specific point sources. Finally, IS can spatially characterize the structure of extended enhancements, such as volcanic plumes, to better constrain spatial extent and transport.

In recent times, AVIRIS-C has been successfully used to find local gas enhancements in the VIS-SWIR (Thorpe et al. 2012, 2013). Researchers generated images of industrial stack plumes (Dennison et al. 2013) as well as natural seeps such as coal oil point (Roberts et al. 2010; Bradley et al. 2011). Promising results have also been obtained for mapping nitrogen dioxide $\left(\mathrm{NO}_{2}\right)$ sources, such as the Zurich (Switzerland) airport, a waste incinerator

\footnotetext{
1 A sounding system measures the intensity of radiation to provide information about a particular property as a function of height in the atmosphere.
} 

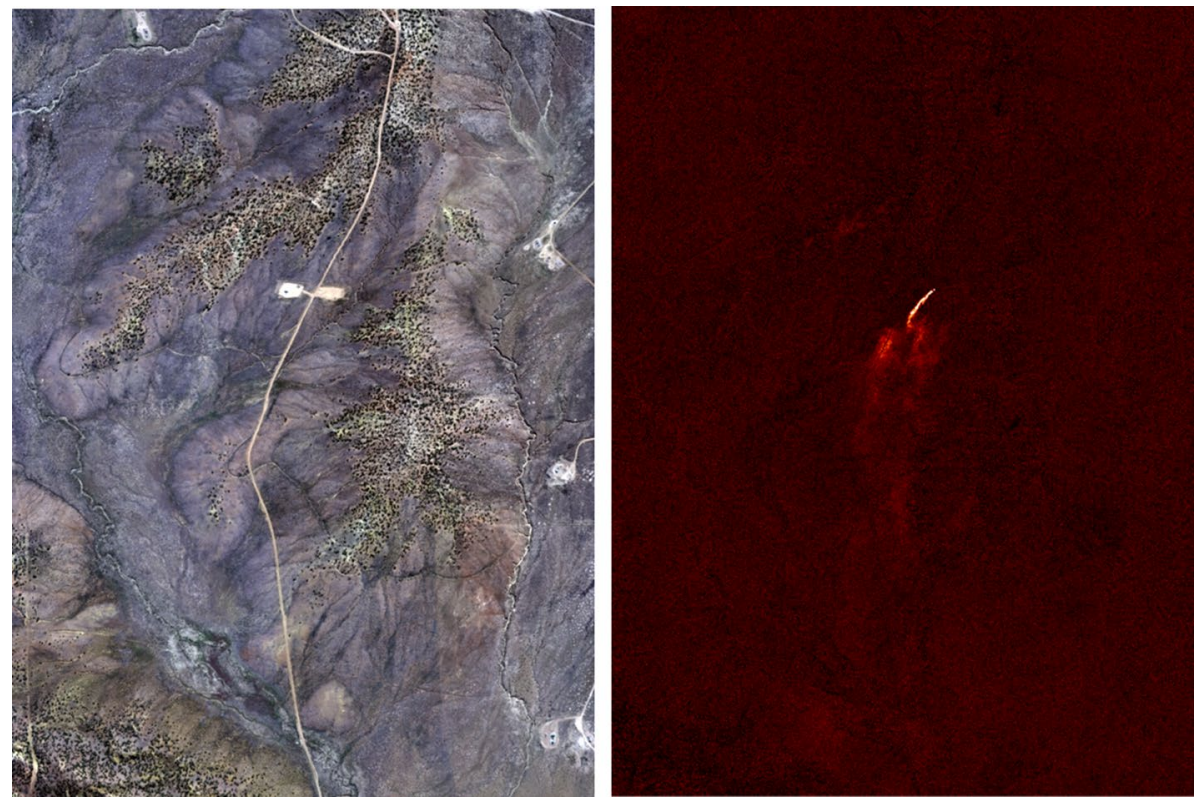

Fig. 8 (Left) True color segment of an AVIRIS-NG flight line acquired in 2014 from the Four Corners Campaign with spectroscopic data available from http://avirisng.jpl.nasa.gov. (Right) $\mathrm{A} \mathrm{CH}_{4}$ retrieval using the technique of Thompson et al. (2015b) shows a plume emanating from a gas well pad. Brighter pixels correspond to higher local enhancements

and motorways, from the Airborne Prism Experiment (APEX) imaging spectrometer (Popp et al. 2012). AVIRIS-C overflew the Hawaiian volcano at Kilauea (USA), providing the first ever map of $\mathrm{CO}_{2}$ concentrations in a volcanic plume (Spinetti et al. 2008). The study of an AVIRIS-C image of a biomass plume from a prescribed fire in Quinault, Washington, USA, by Marion et al. (2004, 2006), Alakian et al. $(2008,2009)$ and Deschamps et al. $(2012,2013)$ and highlighted the need to correct the radiative effect of aerosols in the $\mathrm{CO}_{2}$ absorption band at $2000 \mathrm{~nm}$ to accurately derive $\mathrm{CO}_{2}$ concentration maps in strong optically thick smoke plume. The next-generation AVIRIS (AVIRIS-NG) instrument (Hamlin et al. 2011) offered greater sensitivity in comparison to AVIRIS-C thanks to higher signalto-noise ratios (SNRs) and finer spectral sampling. Controlled release experiments have characterized the sensitivity of AVIRIS-NG at multiple wind speeds and altitudes (Thorpe et al. 2016).

In recent years, VIS-SWIR IS has been increasingly used for wide-area surveys to locate, characterize and quantify gaseous leaks related to the oil and gas industry. This is further assisted by the recent incorporation of detection algorithms into real-time analysis on-board the aircraft, permitting radiometric calibration, detection, quantification, mapping and finally geolocation by ray tracing with digital elevation maps and camera models (Thompson et al. 2105b). These operations execute immediately, generating results to a real-time display so that operators can adjust future flight lines and guide field teams that deploy instruments in situ. This capability was introduced during an AVIRIS-NG campaign in 2014, demonstrated the ability to map oil- and gas-related emissions (Thompson et al. 2105b) and observed plumes from a landfill in the Los Angeles Basin, California, USA 
(Krautwurst et al. 2017). After that, AVIRIS-NG was acquired jointly with the HyTES instrument operating in thermal ranges (Hulley et al. 2016), and other National Oceanic and Atmospheric Administration (NOAA) and university-sponsored teams, to characterize the Four Corners area of the USA. This area had been identified as a $\mathrm{CH}_{4}$ emission "hot spot," but the attribution of this emission to specific sources was not well understood (Frankenberg et al. 2015). Two aircrafts mapped a large fraction of this region, identifying over 200 distinct anthropogenic sources (Fig. 8) including gas well pad unloading events, drilling operations, storage venting and emissions from processing facilities (Frankenberg et al. 2016) based on methane spectral absorption features (Fig. 2) from AVIRIS-NG (Fig. 7). In addition, the IS data detected multiple underground pipeline leaks from transmission lines. These measurements demonstrated the use of IS to provide a reliable statistical characterization of emission sources and accounted for a large fraction of the overall emissions observed in the region.

After the Four Corners survey in 2014, the number of $\mathrm{CH}_{4}$ investigations using imaging spectrometers in the USA has grown considerably in a short time. VIS-SWIR and thermal sensors viewed the Aliso Canyon, Southern California, USA, event, a large accidental release of methane from an underground storage facility in autumn 2015-winter 2016. The Aliso Canyon event was the largest single $\mathrm{CH}_{4}$ point-source-emitter detected to date and was successfully observed by the NASA EO-1 Hyperion (Pearlman et al. 2001) instrument on-board the Earth-orbiting EO-1 spacecraft (Thompson et al. 2016). The EO-1 spacecraft was only able to image the plume under sub-optimal illumination conditions, resulting in an extremely low signal-to-noise ratio (SNR). Nevertheless, it observed the plume morphology on three occasions to achieve the first ever detection and attribution of a single $\mathrm{CH}_{4}$ point source from orbit. In 2016, the state of California began an extended campaign by using AVIRIS-NG to characterize $\mathrm{CH}_{4}$ point sources in key areas across the state (Duren et al. 2017). This represented the first systematic, multi-sector effort involving remote sensing technology. Through these efforts, spectroscopic $\mathrm{CH}_{4}$ imaging has continued to evolve from a purely scientific method to practical policymaking support tool, and is an important component of a multi-tier $\mathrm{CH}_{4}$-accounting regime (Hopkins et al. 2016).

\subsection{Naturally Occurring Hazardous Soils and Rocks}

Expansive or swelling clays and clay shales are soils that have the potential to significantly change their volume with changes in moisture, hence, with wet and dry cycles, these volumetric changes can cause extreme pressure in the soil profile resulting in severe engineering problems (building and road cracks, foundation deformation), agricultural problems (root cutting), as well as environmental problems (drying up of the sub-surface horizon, floods, landslides) causing billions of dollars of damage worldwide every year, more than all other natural hazards combined (Jones and Jefferson 2012). Expansion of soils is a result of a combination of minerals present in the matrix (mainly clay mineral species and content), water quality (fresh or saline), organic matter content, availability of $\mathrm{Ca}$ ions, as well as the origin and content of free iron oxides. In particular, aluminium-rich smectite (montmorillonite) (see Fig. 2 for spectrum) has been shown to be the main culprit for the expansive potential hazard. IS with its capabilities for direct identification of the key culprit constituent minerals in soils is potentially an attractive tool for rapid and inexpensive regional and local mapping to augment standard engineering and geological methods which are time-consuming and expensive, and do not provide spatial coverage. 

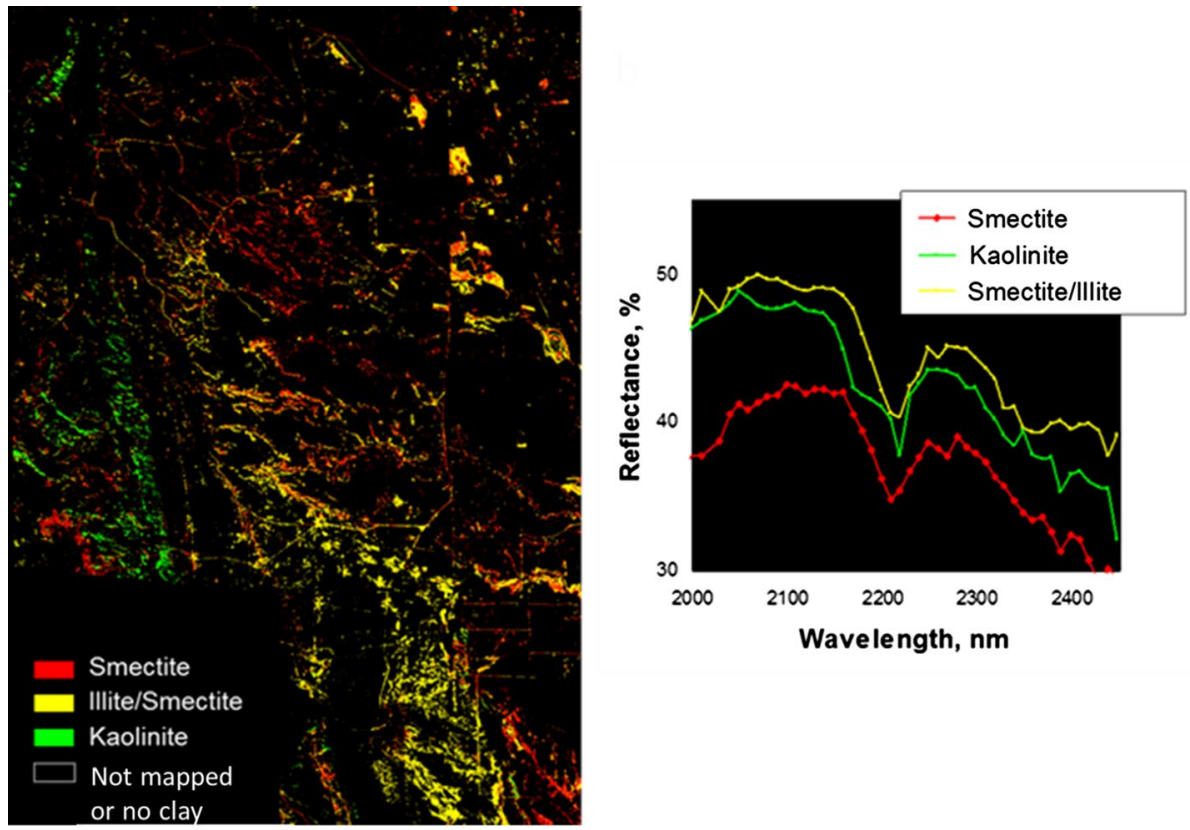

Fig. 9 Regional map for the Front Range Urban corridor near Denver, Colorado, USA of expansive clays exposed at the surface and of swelling soils hazards (red: high, yellow: medium, green: low/none) based on airborne AVIRIS-C IS data. Figure modified from Chabrillat and Goetz (2006)

Pioneering work from Chabrillat et al. (2002) demonstrated the potential of IS to detect and map swelling clays with a study along the Front Range Urban corridor near Denver, Colorado, USA, a rapidly growing urban area that was severely affected by swelling soils. This was due to the heaving bedrock hazard associated with the coincidence of steeply dipping layers of sedimentary bedrock having dip angles of greater than $30^{\circ}$, and zones of expansive bedrock that swell in volume when excess moisture was introduced. Chabrillat et al. (2002) showed that VIS-SWIR IS from AVIRIS-C can be used to discriminate pure smectite from mixed layers of illite/smectite samples (associated with decreasing swelling potential), and thus can be used to produce a map of hazards for the studied area (e.g., Chabrillat et al. 2002; Chabrillat and Goetz 2006). Spectral discrimination and identification of variable clay mineralogy (smectite, illite/smectite and kaolinite), related to variable swelling potential, was possible from airborne IS data at high spatial resolution $(<5 \mathrm{~m})$, and on a regional basis with slightly lower spatial resolution $(20 \mathrm{~m})$ (Fig. 9). Spectral feature fitting was used to discriminate the swelling soils, and the level of success was dependent on the level of the exposures and the variable mineralogy, and the presence of partial vegetation cover.

Subsequently, many studies extended the concept and extended the knowledge on swelling soils' optical properties (e.g., Kariuki et al. 2004; Bourguignon et al. 2007; Yitegasu et al. 2009; Dufrechou et al. 2016) and their link to potential swelling hazard. Nowadays, IS is a proven method for the identification and mapping of the occurrences of swelling soils, as demonstrated in many regions around the world (the USA, Kenya and France). Such optical remote sensing methods, coupled with a reduced amount of field and laboratory 

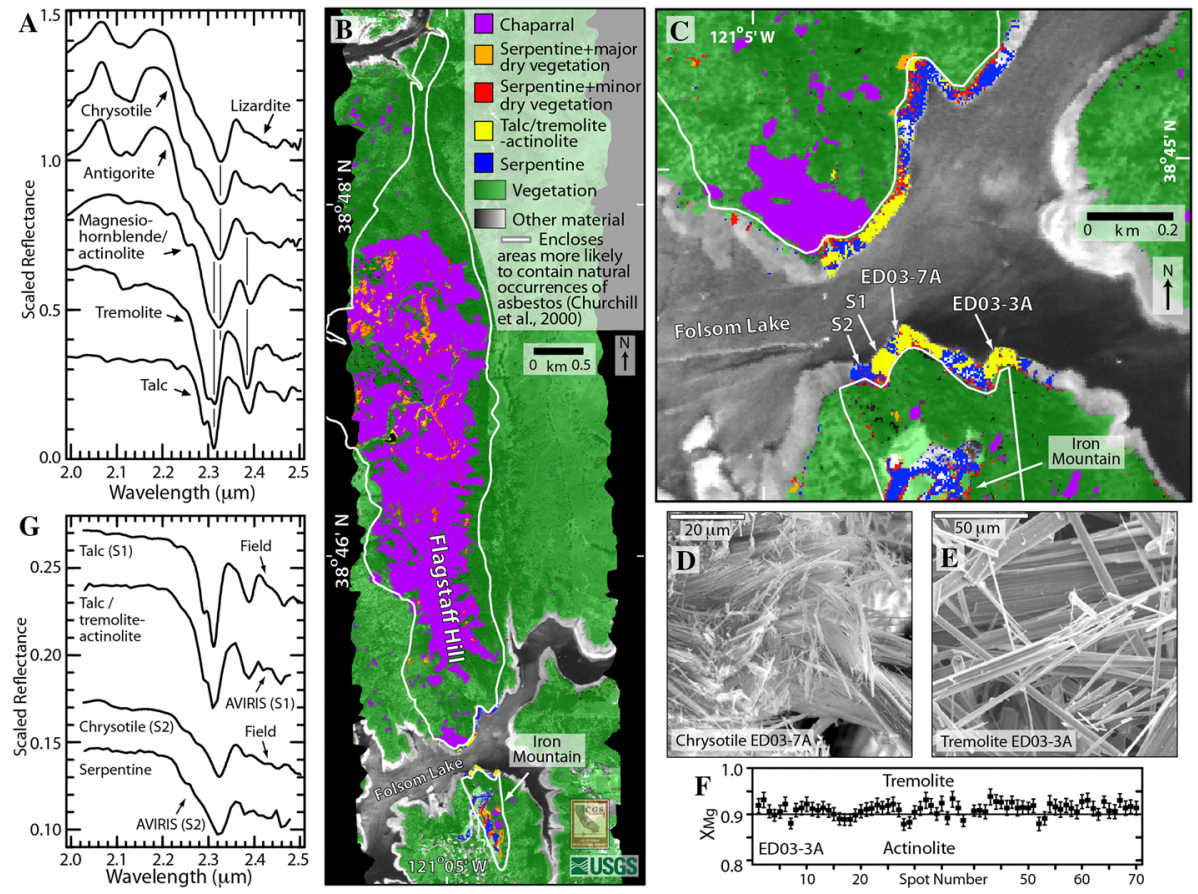

Fig. 10 A Reflectance spectra of some minerals associated with serpentine deposits in Calvaras County in California, USA. B, C Potentially asbestos-bearing minerals and vegetation preferentially growing on asbestos-bearing rocks in western El Dorado County in the Sierra Nevada of California, USA, mapped using IS data acquired using the AVIRIS-C. D, E Scanning electron micrograph of chrysotile fiber bundles. F Comparison of spectra extracted from AVIRIS-C to spectra collected in the field collected over the Red Hill Complex, in the foothills of the Sierra Nevada, California, USA. Figure sourced from Swayze et al. (2009)

analyses, can offer a practical tool for town planners, as long as the swelling soils are adequately exposed at the surface and the instrument has a high enough SNR particularly in the SWIR.

Hazards related to asbestos exposure and their detrimental implications for human health are well documented (International Agency for Research on Cancer 2012; van Oss et al. 1999). Asbestos is a morphological term describing mineral fibres with lengths that are much greater than their widths. Consequently, the asbestos name does not always correspond to a mineral name. A variety of minerals have asbestiform crystal habits (Ross 1999). The two main categories used commercially for asbestos insulation are chrysotile, the only fibrous member of the serpentine mineral group, and several fibrous amphibole minerals comprised of anthophyllite, amosite, crocidolite, tremolite and actinolite. IS can be used to identify some of these minerals such as chrysotile (see spectrum and related diagnostic feature in Fig. 2), and indeed, there have been a handful of case studies on the use of the technology for identifying asbestos-bearing rocks and man-made materials (e.g., Marino et al. 2000; Clark et al. 2001, 2003b; Swayze et al. 2004, 2009; Frassy et al. 2014; Massarelli et al. 2017; Bonifazi and Serranti 2016).

Although there is high public awareness of the hazards related to insulation and other manufactured goods, and even legacy mines, issues related to naturally occurring 


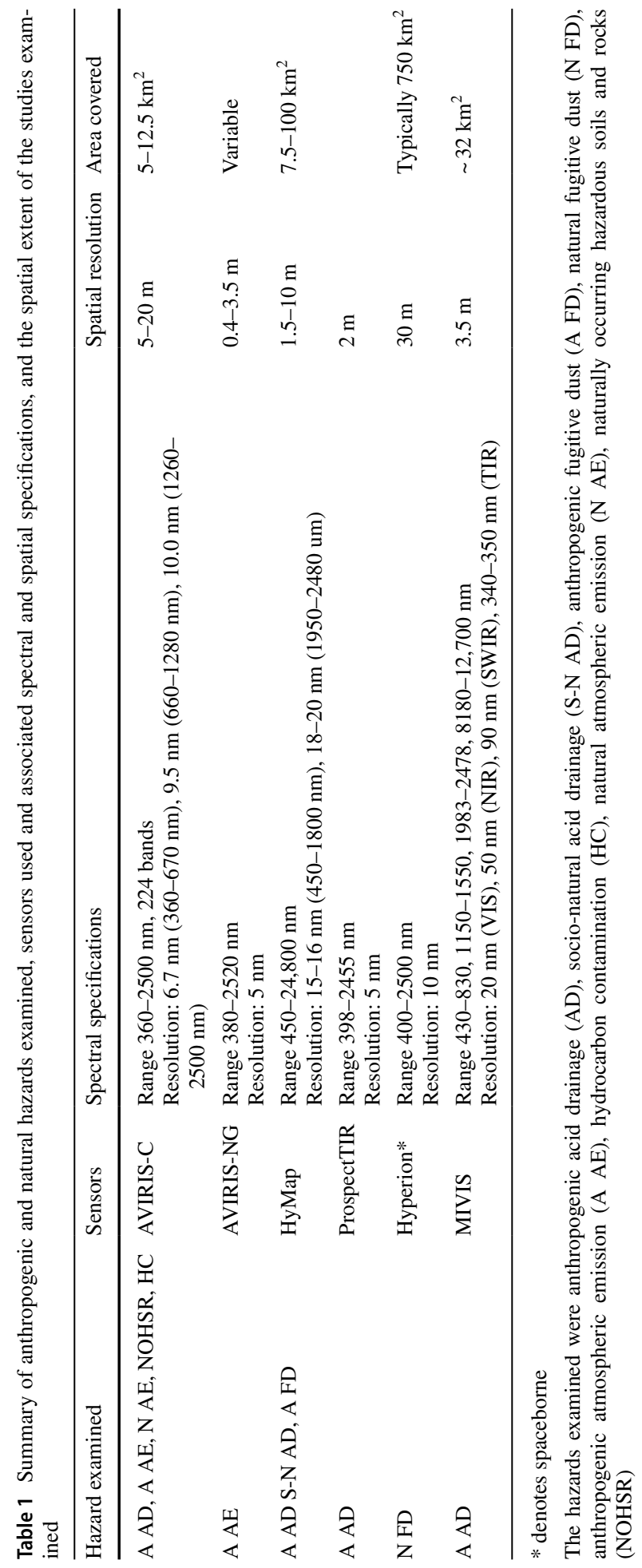




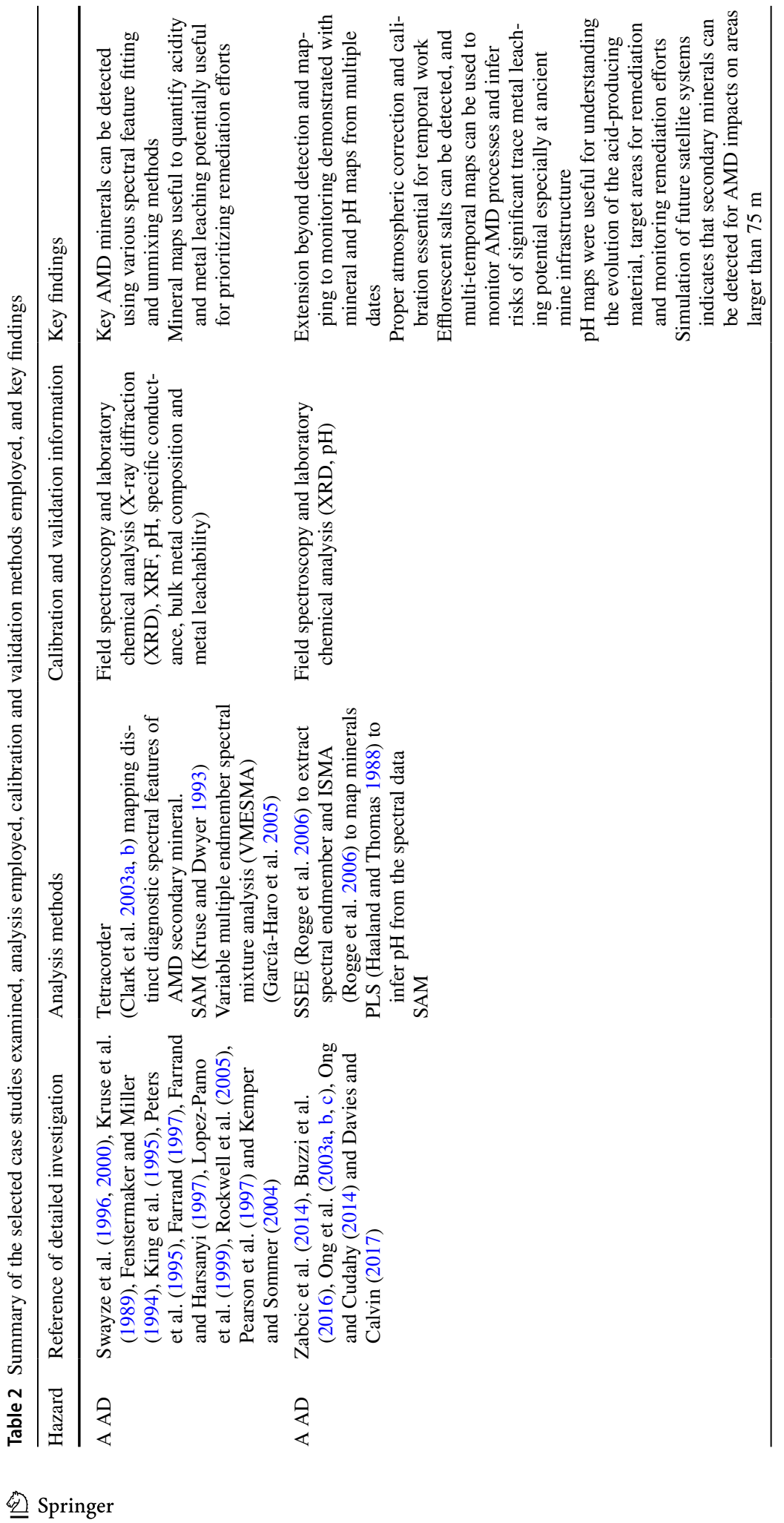




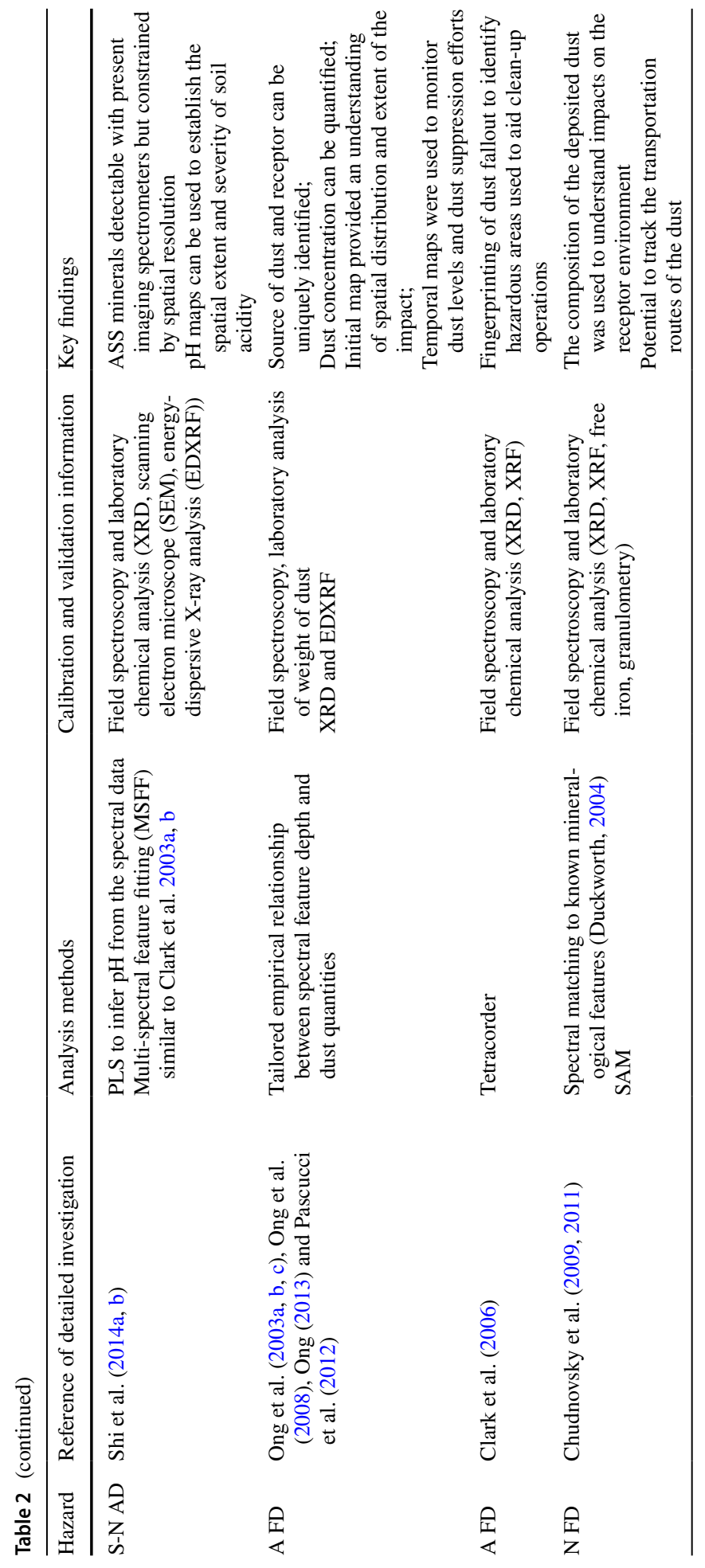




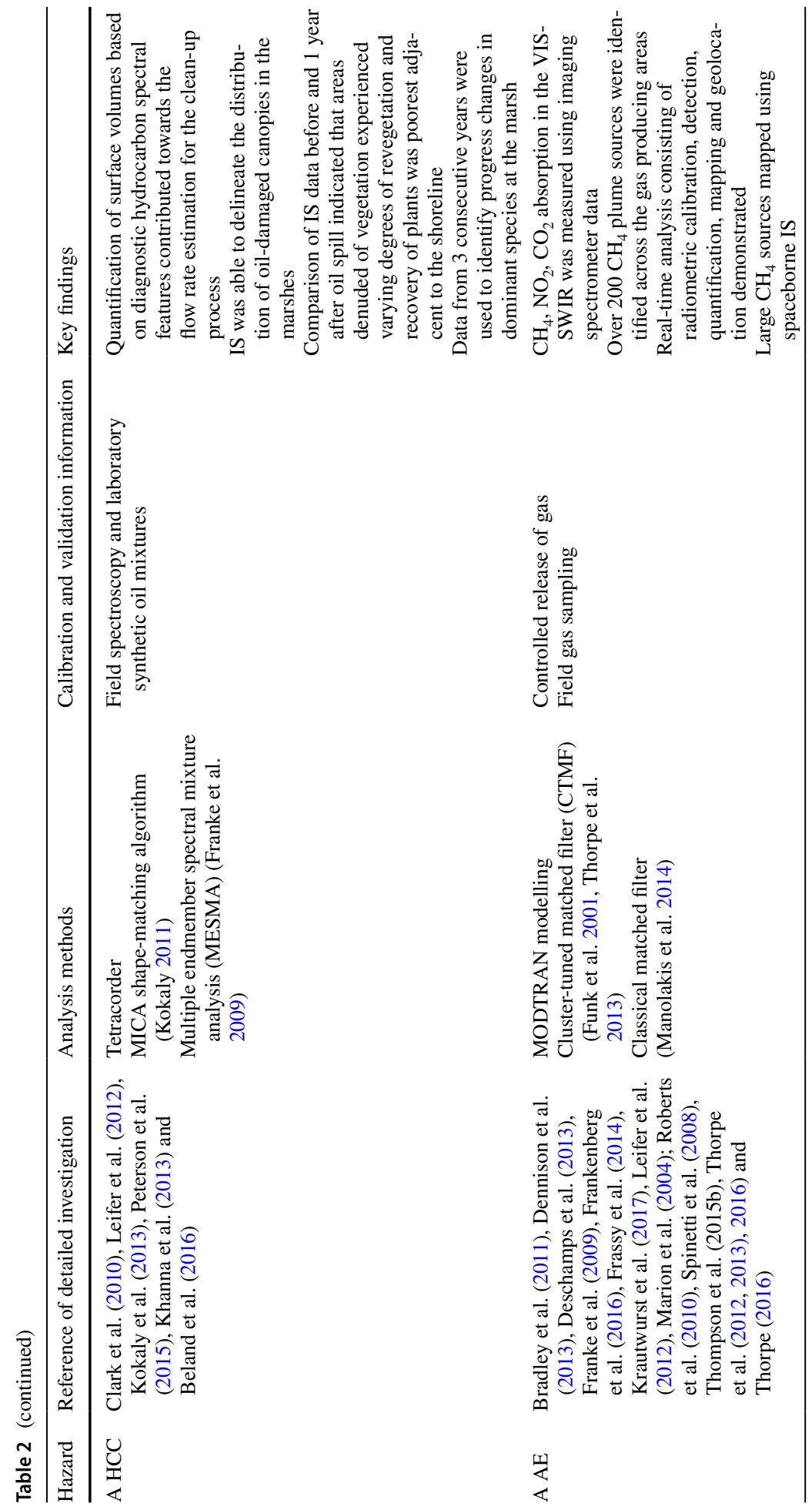




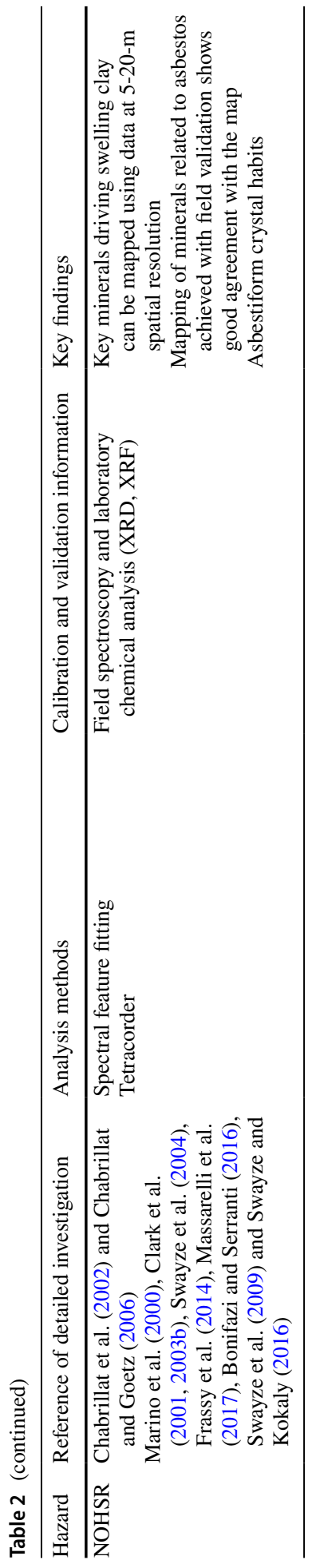


asbestos (NOA) are not as commonly known even though it can potentially be a hazard for people living near its sources (Pan et al. 2005). For example, in central and northern California, USA, chrysotile and fibrous amphiboles like tremolite and actinolite are dominantly, but not exclusively, associated with serpentinite and ultramafic rocks, which are common in the Sierra Nevada, Coast Ranges and Klamath Mountains. Consequently, it is important that these rock types be identified to help reduce the public's exposure to potentially NOA-bearing dust generated during building and outdoor activities.

A study using data collected by AVIRIS-C in western El Dorado County in the Sierra Nevada of California, USA, demonstrated the use of IS for mapping the distribution of these potentially NOA-bearing serpentinite and ultramafic rocks (Swayze et al. 2009; Swayze and Kokaly 2016). Here, direct detection of potentially NOA-bearing minerals exposed in rock outcrops and mapping of vegetation cover that preferentially grows on these rocks as a surrogate of NOA-bearing minerals was achieved using Tetracorder as shown in Fig. 10 where the fibrous chrysotile was mapped together with other non-fibrous serpentine minerals and the potentially fibrous tremolite and actinolite were combined into a single spectral category called talc/tremolite-actinolite (T/TA). Compared to traditional field mapping, nearly all of the high-density clusters of pixels mapped as potentially NOA: that is serpentine, serpentine + minor dry vegetation and T/TA, either fall inside or within a few hundred metres of the boundaries identified by Churchill and Hill (2000) and Churchill et al. 2000 (i.e. shown by white polygons in Fig. 10B, C) except where transported by human activities or exposed by low-water condition of Folsom Lake. Field validation work verified the exposures of NOA along the Folsom Lake shoreline as seen in Fig. $10 \mathrm{C}$ to be chrysotile-bearing serpentinite and tremolite-talc schist. Further, there is potential to identify serpentine by mapping chaparral as these species of vegetation have a local affinity for serpentine (Kruckeberg 1984).

Spectral maps that integrate information from substrate-dependent vegetative classification and lithologically independent mineral identification can be used as a tool for delineating areas more likely to contain NOA. These maps can also be used to identify roads surfaced with serpentine aggregate, locate areas in need of dust control or remediation and help fill gaps in geologic mapping where access is limited.

\subsection{Summary Discussions}

Use cases on the application of IS for anthropogenic acid drainage (A AD), socio-natural acid drainage (S-N AD), anthropogenic fugitive dust (A FD), natural fugitive dust (N FD), anthropogenic atmospheric emission (A AE), hydrocarbon contamination (HC C), natural atmospheric emission ( $\mathrm{N} \mathrm{AE}$ ), naturally occurring hazardous soils and rocks (NOHSR) (reference shown in Table 2) were examined as part of this paper.

All the case studies examined showed that diagnostic spectral features in the VIS-SWIR range were crucial for providing identification and quantification of the hazards. Specifically, the hazardous materials for A AD, S-N AD, A FD, N FD and NOHSR all have unique mineralogical spectral features that can be discriminated across the VIS-SWIR. In addition, hazardous A AE and $\mathrm{HC} \mathrm{C}$ contamination also has spectrally distinguishing features across the VIS-SWIR region. These features and their associated shapes/geometries were key to accurate identification and quantification of the hazardous materials. These identification and quantification capabilities then translated to the enabling of better assessments of risks as shown for all case histories, improved targeting of emergency responses 


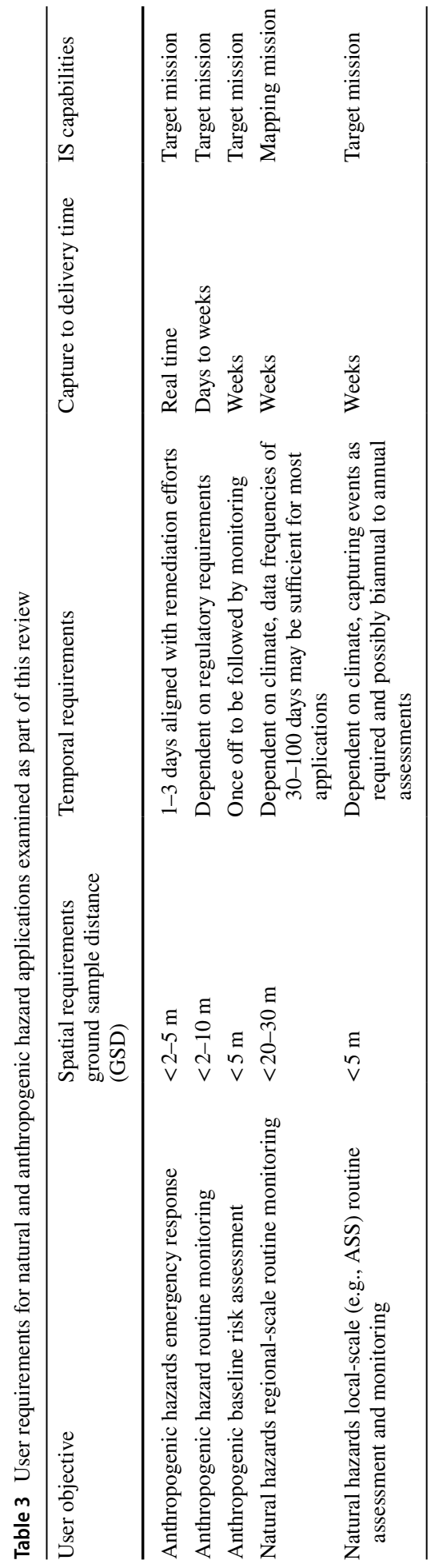


demonstrated by case histories in A FD and $\mathrm{HC} \mathrm{C}$, and enhanced understanding of the progress of remediation efforts shown for monitoring A AD, A FD and $\mathrm{HC} C$ hazards.

It is important to note that for all the case studies examined, the data had to be processed to remove atmospheric attenuation. In addition, recalibration (wavelength and radiometric) was also essential for the retrieval of accurate data particularly for multi-temporal monitoring. There are now operational techniques for this process (Richter and Schläpfer 2002; FLAASH, Adler-Golden et al. 1998; SODA, Rodger 2011; CSES 1997; Berk et al. 1998; Berk 2005; Carrère and Conel 1993). To encourage the uptake of the technology, it may be important for data providers to consider the delivery of data with this level of processing. In addition, for spaceborne IS, international networks such as the Radiometric Calibration Network (RadCalNet) (RadCalNet 2018) should prove to be valuable for radiometric calibration.

A variety of techniques have been developed to enable the detection and quantification of these natural and anthropogenic hazards starting with simple ratios, unmixing algorithms including different variants of matched filters (Stocker et al. 1990; Manolakis et al. 2009; Funk et al. 2001), spectral feature matching (Chabrillat et al. 2016; Clark et al. 2003a), spectral deconvolution approaches (Sunshine et al. 1990, Brossard et al. 2016) and the employment of chemometric methods such as PLS (Haaland and Thomas 1988) (see more details in Table 2). A notable development relevant to emergency response is the work by Thompson et al. (2105b) which provides near-real-time capability across the complete chain of processing from radiometric correction to information products. Such capabilities would enable IS technologies to be more readily deployed operationally. If such systems were to be developed further, it would extend the potential for future spaceborne IS to real-time decision-making in disaster management. In the area of risk assessments and monitoring linked to regulatory requirements, the method developed by Ong (2013) included an assessment of the uncertainties in the method essential for meeting the compliance requirements and hence is at a state where it is ready to be operationally deployed.

Associated with the development of these analysis techniques, spectral libraries and associated corroborative information were compiled to better understand the material, background, and mixtures. This has resulted in quite a few new and extended reference spectral libraries (e.g., for AMD secondary minerals and asbestos (Kokaly et al. 2017; Crowley et al. 2003); for oils of varying composition and oil emulsions of different oil:water ratios and thicknesses (Lammoglia and Souza Filho 2011, 2012; Clark et al. 2010; Kokaly et al. 2017); for mixtures of oils with a variety of minerals and soils (Scafutto and Souza Filho 2016; Scafutto et al. 2016, 2017)). These techniques and spectral libraries provide a strong basis for the application of IS for natural and anthropogenic hazards detection, assessment and monitoring.

The data used were acquired from a range of VIS-SWIR imaging spectrometers (see Table 1) mainly from airborne platforms except for EO-1 Hyperion. Note that no unmanned autonomous systems (UAS) were examined as there are insufficiently documented case histories deploying the full VIS-SWIR. The spatial resolutions used the range from 0.4 to $20 \mathrm{~m}$, but most of them were less than $5 \mathrm{~m}$ and the areas covered was generally small with the largest being $100 \mathrm{~km}^{2}$. Generally, the spatial resolution chosen was governed by the size of the impacted area and the ability to discriminate the spectral feature. Therefore, the choice of the optimal spatial resolution cannot be generalized for any application. 


\section{User and Observational Requirements}

A diverse range of applications of IS for natural and anthropogenic hazards (see Table 2) for risk assessments, emergency response, targeting clean-up/remediation and monitoring remediation efforts have been examined in this paper. The area of impact varied as well as the response time required to attend to the hazard and the remediation impacts to be seen. The observational requirements which vary according to the needs of the hazard and user community, are summarized in Table 3 and are based on the use case examined.

In general, the temporal requirements depend on whether the data would be used for emergency responses, routine monitoring or baseline assessments. If the applications are for emergency responses, spaceborne pointing capabilities would be ideal allowing capture immediately following an accidental oil spill, tailings dam breach or gas/chemical release, earthquake, flood, wildfire or terrorist attack. Repeat observations every several days aligned with the schedule of the clean-up process would be useful to help to guide and focus the remediation effort. Such applications would require the data to be provided to the clean-up team in real time or at least over a very short time frame (that is, hours). Strategies such as on-board processing and fast downlink are critical so that data can be incorporated into the clean-up framework. After containment of the pollutant, the frequency of acquisition likely could be reduced to once per a couple of months depending on the progress of remediation. Regarding spatial requirements, most emergency responses require spatial resolutions of $5 \mathrm{~m}$ or finer. For example, the data captured for the WTC attack were at $2 \mathrm{~m}$ spatial resolution.

If the user requirement is for routine monitoring, in general, a moderate repeat time of 30 days will suffice for most applications. For anthropogenic hazards, the temporal frequency of data acquisition is usually determined by the regulatory requirements; whereas for natural hazards, the temporal frequency may be determined by the need to capture critical climatic events or changes as they occur. For example, in the monitoring of dust resulting from iron ore handling, current routine ground monitoring using dust depositional gauges is conducted monthly, and hence the availability of remotely sensed dust maps in line with this schedule would be sufficient. Further, for hydrocarbon monitoring, continuous, natural releases of hydrocarbons are not constrained within a specific collection window, but if pollutants are on the water surface, wind conditions may constrain data collection. Therefore, a moderate 30-day repeat or longer revisit cycle, which takes surface conditions into account, may be sufficient for their detection, assuming spatial resolution is adequate.

With regard to spatial resolution, anthropogenic hazard applications usually require finer spatial resolutions than natural hazards as monitoring is usually conducted at the local scale, for example within a mineral lease area. Most of the examples examined captured data with the spatial resolutions of 2-5 m. A pixel resolution of $20 \mathrm{~m}$ appears to be sufficient for most natural hazards monitoring applications. However, there are some natural hazard applications such as mapping acid sulphate soils where finer spatial resolutions of less than $5 \mathrm{~m}$ are required as the hazards are usually localized point sources.

One of the most comprehensive studies on spectral requirements was conducted by Swayze et al. (2003). In this study, the effects of spectrometer bandpass, sampling and SNR on the spectral identification of a range of surface materials relevant to anthropogenic and natural hazards was examined. The study results indicated that when the sampling interval (SI) is broad, it is the main factor that drives the ability to identify a material because of spectral aliasing, a condition where absorption features of different materials can resemble 
one another. At narrow SI values relative to the natural full width at half maximum of absorptions, the SNR drives the identification of materials. The bandpass (BP) is less critical to spectral identification than the SI or SNR because broadening the BP does not induce spectral aliasing. It is possible to use the results from studies such as Swayze et al. (2003) to define the optimum combination of BP, SI and SNR for particular applications. Therefore, if we assume the materials examined in Swayze et al. (2003) are fair representations of surface materials encountered for natural and anthropogenic hazards, then the lowest SI to achieve correct spectral identification at $50 \%$ of the time for the electronic region $(400-1350 \mathrm{~nm})$ is around $13 \mathrm{~nm}$, and $10 \mathrm{~nm}$ for the vibrational region (1350-2500 nm). If higher accuracy is desired finer sampling will be required. These values are in the range of the specifications of future spaceborne IS missions such as Environmental Mapping and Analysis Program (EnMAP, Guanter et al. 2015), Hyperspectral Imager Suite (HISUI, Matsunaga, et al. 2018), Surface Biology and Geology (SBG, Green 2018, previously Hyperspectral InfraRed Imager (HyspIRI), Lee et al. 2015), Hyperspectral Imaging Mission for the Environment (CHIME, Nieke and Rast 2018) and Hyperspectral Precursor of the Application Mission (Loizzo et al. 2018). The SNR specifications for future spaceborne missions are also higher than the SNR required for the identification of the different materials examined.

It is important to note that the Swayze et al. (2003) study examined pure materials, and in real-world situations usually mixtures of materials are encountered; therefore, further studies to examine these implications are required. Additionally, Swayze et al. (2003) did not cover hydrocarbons, gaseous emissions and aerosols. It would be useful to conduct studies to examine the requirements for spectral identification of these materials.

\section{Challenges and Future Directions}

This paper examined the use of VIS-SWIR IS to inform decision-making on natural and anthropogenic hazards. Specifically, several case histories for management of A AD, S-N $\mathrm{AD}, \mathrm{A}$ FD, N FD, A AE, HC C, NOHSR representative of some significant societal and global challenges were examined. These case histories were chosen predominantly to highlight the distinguishing capability of VIS-SWIR IS - the ability to provide quantitative diagnostic information. These diagnostic data generally cannot be obtained at the quantification level, speed, spatial comprehension or resolution from current operational remote sensing systems.

Although the case studies provided compelling evidence for the use of IS, the technology is currently still generally considered to be a scientific tool because of the lack of operational systems, the perceived complexity when using the data and the high costs of acquisitions. The projected launch of spaceborne IS sensors in the near future should fill a proportion of this gap especially for applications where the areas of impact is large as found by Davies and Calvin (2017). However, for many of the case histories examined, the small areas of impact preclude the use of these near term spaceborne IS, which generally has spatial resolution of $30 \mathrm{~m}$. For these cases, in the midterm, there are a small number of high spatial resolution spaceborne IS systems being suggested. Additionally, high quality and moderate cost of off the shelf sensors are becoming more accessible. These nextgeneration technologies may have the potential to fill this gap. With the latter, there is still the issue of operational costs with airborne systems. Here, the possibilities to couple UAS with miniaturized systems operating across the complete VIS-SWIR ranges, albeit not yet 
currently available, are a long-term future opportunity to overcome some of the challenges with current operational systems.

With regard to the availability of scientific tools and knowledge to handle the data, the associated studies accompanying many spaceborne missions and the availability of commercial off the shelf sensors have seen an incremental increase in the tools being made publically available, such as those provided by the EnMAP mission (van der Linden et al. 2015). The van der Linden et al. (2015) study shows that many analysis methods have been developed and many of them have also been verified. There is an opportunity now to capture these verified methods in analysis packages in readiness for future spaceborne IS so that downstream products can be quickly accessed enabling faster uptake of the technology.

The challenges and opportunities for the scientific community when future spaceborne IS and next-generation sensors from airborne or UAS platforms become available will be ensuring consistency between data from different sensors, handling, processing, integrating and delivering the large volumes of data and most importantly translating the data to information that meets specific unmet needs of the user community in a form that can be digested/understood by them. The latter is especially important for transferring the technology from a scientific to an operational tool. Good progress has been made by the airborne community in this area especially by organizations such as the European Facility for Airborne Research (EUFAR, http://www.eufar.net/tools/) which has developed an extensive variety of tools for these purposes. These tools could potentially be a good basis for future spaceborne IS missions.

In addition to the consistency of products, the downstream information products must be independently validated using current trusted practices and uncertainties quantified before the IS derived measurement can be integrated into operational monitoring services. Most of the case histories captured in this paper demonstrated this aspect where the products have been independently validated.

Acknowledgements This paper is an outcome of a Workshop on Requirements, capabilities and directions in spaceborne IS held at the International Space Science Institute (ISSI) in Bern, Switzerland, in November 2016. The support of ISSI is gratefully acknowledged. A portion of this research was carried out at the Jet Propulsion Laboratory, California Institute of Technology, under contract with the National Aeronautics and Space Administration (NASA). US Government support is acknowledged.

Open Access This article is distributed under the terms of the Creative Commons Attribution 4.0 International License (http://creativecommons.org/licenses/by/4.0/), which permits unrestricted use, distribution, and reproduction in any medium, provided you give appropriate credit to the original author(s) and the source, provide a link to the Creative Commons license, and indicate if changes were made.

\section{References}

Achterberg EP, Braungardt C, Morley NH, Elbaz-Poulichet F, Leblanc M (1999) Impact of Los Frailes mine spill on riverine, estuarine and coastal waters in southern Spain. Water Res 33:3387-3394. https://doi. org/10.1016/S0043-1354(99)00282-1

Adler-Golden S, Berk A, Bernstein LS, Richtsmeier S (1998) FLAASH, A Modtran4 Atmospheric correction package for hyperspectral data summaries of the 7th annual JPL Airborne earth science workshop, Jet Propulsion Laboratory Publication 98-21 vol 1, AVIRIS workshop, Jet Propulsion Laboratory, California Institute of Technology, Pasadena

Akcil A, Koldas S (2006) Acid mine drainage (AMD): causes, treatment and case studies. J Clean Prod 14:1139-1145. https://doi.org/10.1016/j.jclepro.2004.09.006

Alakian A, Marion R, Briottet X (2008) Remote sensing of aerosol plumes: a semi-analytical model. Appl Opt 47:1851-1866 
Alakian A, Marion R, Briottet X (2009) Retrieval of microphysical and optical properties in aerosol plumes with hyperspectral imagery: 1-APOM method. Remote Sens Environ 113:781-793

Alpers CN, Blowes DW, Nordstrom DK, Jambor JL (1994) Secondary minerals and acid mine-water chemistry. In: Blowes DW, Jambor JL (eds) The environmental geochemistry of sulfide mine-wastes, short course handbook, vol 2. Waterloo, Mineralogical Association of Canada, pp 247-270

Beland M, Roberts DA, Peterson SH, Biggs TW, Kokaly RF, Piazza S, Ustin SL (2016) Mapping changing distributions of dominant species in oil-contaminated salt marshes of Louisiana using imaging spectroscopy. Remote Sens Environ 182:192-207. https://doi.org/10.1016/j.rse.2016.04.024

Berk A, Bernstein LS, Anderson GP, Acharya PK, Robertson DC, Chetwynd JH, Adler-Golden SM (1998) MODTRAN cloud and multiple scattering upgrades with application to AVIRIS. Remote Sens Environ 65:367-375

Berk A et al (2005) MODTRAN 5: a reformulated atmospheric band model with auxiliary species and practical multiple scattering options: update. In: Defense and security, SPIE, vol 5806

Bigham JM, Schwertmann U, Pfab G (1996) Influence of $\mathrm{pH}$ on mineral speciation in a bioreactor simulating acid mine drainage. Appl Geochem 11:845-849

Bonifazi G, Serranti S (2016) Hyperspectral imaging for asbestos identification in cement products. SPIE 1:1. https://doi.org/10.1117/2.1201608.006645

Bourguignon A, Delpont G, Chevrel S, Chabrillat S (2007) Detection and mapping of shrink-swell clays in SW France using ASTER imagery. In: Teeuw RM (ed) Mapping hazardous terrain using remote sensing, vol 283. Geological Society, Special Publications, London, pp 117-124

Bradley ES, Leifer I, Roberts DA, Dennison PE, Washburn L (2011) Detection of marine methane emissions with AVIRIS band ratios. Geophys Res Lett 38:10

Brossard M, Marion R, Carrère V (2016) Deconvolution of SWIR reflectance spectra for automatic mineral identification in hyperspectral imaging. Remote Sens Lett 7(6):581-590. https://doi. org/10.1080/2150704X.2016.1168946

Burns RG (1993) Mineralogical applications of crystal field theory, 2nd edn. Cambridge Topics in Mineral Physics and Chemistry, Cambridge

Buzzi J, Riaza A, García-Meléndez E, Carrère V, Holzwarth S (2016) Monitoring of river contamination derived from acid mine drainage using airborne imaging spectroscopy (HyMap) data. South West Spain River Res Appl 32:125-136. https://doi.org/10.1002/rra.2849

Cairns B, Carlson BE, Ying R, Lacis AA, Oinas V (2003) Atmospheric correction and its application to an analysis of Hyperion data. IEEE Trans Geosci Remote Sens 41(6):1232-1245

Carrère V, Conel JE (1993) Recovery of atmospheric water vapor total column abundance from imaging spectrometer data around $940 \mathrm{~nm}$ - sensitivity analysis and application to airborne visible/infrared imaging spectrometer (AVIRIS) data. Remote Sens Environ 44:179-204

Chabrillat S, Goetz AFH (2006) Remote sensing of expansive soils: use of hyperspectral methodology for clay mapping and hazard assessment. In: Ali Al-Rawas A, Goosen MFA (eds) Expansive soils: recent advances in characterization and treatment. Taylor \& Francis, London, pp 187-209

Chabrillat S, Goetz AFH, Olsen HW, Krosley L (2002) Use of hyperspectral images in the identification and mapping of expansive clay soils and the role of spatial resolution. Remote Sens Environ 82(2-3):431-445

Chabrillat S, Guillaso S, Rabe A, Foerster S, Guanter L (2016) From HYSOMA to ENSOMAP - A new open source tool for quantitative soil properties mapping based on hyperspectral imagery from airborne to spaceborne applications. In: EGU General Assembly 2016, Vienna, Austria

Chabrillat S, Ben-Dor E, Cierniewski J, Gomez C, Schmid T, van Wesemael B (2019) Imaging spectroscopy for soil mapping and monitoring. Surv in Geophys. https://doi.org/10.1007/s10712-019-09524 -0 (this issue)

Chudnovsky A, Ben-Dor E, Kostinski AB, Koren I (2009) Mineral content analysis of atmospheric dust using hyperspectral information from space. Geophys Res Lett. https://doi.org/10.1029/2009g1037922

Chudnovsky A, Kostinski A, Herrmann L, Koren I, Nutesku G, Ben-Dor E (2011) Hyperspectral spaceborne imaging of dust-laden flows: anatomy of Saharan dust storm from the Bodele depression. Remote Sens Environ 115:1013-1024. https://doi.org/10.1016/j.rse.2010.12.006

Churchill RK, Hill RL (2000) A general location guide for ultramafic rocks in California: areas more likely to contain naturally occurring asbestos. California Department of Conservation, Division of Mines and Geology Open-File Report 2000-19, Sacramento

Churchill RK, Higgins CT, Hill B (2000) Areas more likely to contain natural occurrences of asbestos in western El Dorado County, California. California Department of Conservation, Division of Mines and Geology, Open-File Report 2000-002, Sacramento

Clark RN (1999) Spectroscopy of rocks and minerals, and principles of spectroscopy. In: Rencz A (ed) Manual of remote sensing. Wiley, New York, pp 3-58 
Clark RN, Roush TL (1984) Spectral properties of mixtures of montmorillonite and dark carbon grains: implications for remote sensing minerals containing chemically and physically adsorbed water. J Geophys Res 89:6329-6340

Clark RN, Green RO, Swayze GA, Meeker G, Sutley S, Hoefen TM, Livo KE, Plumlee G, Parvi B, Sarture C, Wilson S, Hageman P, Lamoth P, Vance JS, Boardman J, Brownfield I, Gent C, Morath LC, Taggart J, Theodorakos PM, Adams M (2001) Environmental studies of the world trade center area after the September 11, 2001 attack. U.S. Geological Survey Open-File Report 01-0429

Clark RN, Swayze GA, Livo KE, Kokaly RF, Sutley SJ, Dalton JB, McDougal RR, Gent CA (2003a) Imaging spectroscopy: earth and planetary remote sensing with the USGS tetracorder and expert systems. J Geophys Res 108(E12):5131. https://doi.org/10.1029/2002JE001847

Clark RN, Hoefen TM, Swayze GA, Livo KE, Meeker GP, Sutley SJ, Wilson S, Brownfield IK, Vance JS (2003b). Reflectance spectroscopy as a rapid assessment tool for the detection of amphiboles from the Libby, Montana region. U.S. Geological Survey Open-File Report 03-128

Clark RN, Swayze GA, Hoefen TM, Green RO, Livo KE, Meeker G, Sutley S, Plumlee G, Pavri B, Sarture C, Boardman J, Brownfield I, Morath LC (2006) Chapter 4: environmental mapping of the World Trade Center area with imaging spectroscopy after the September 11, 2001 attack: in Urban Aerosols and Their Impacts: Lessons Learned from the World Trade Center Tragedy vol American Chemical Society, Symposium Series 919. Oxford University Press

Clark RN, Curchin JM, Hoefen TM, Swayze GA (2009) Reflectance spectroscopy of organic compounds: 1. Alkanes J Geophys Res. https://doi.org/10.1029/2008je003150

Clark RN, Swayze GA, Leifer I, Livo KE, Kokaly RF, Hoefen T, Lundeen S, Eastwood M, Green RO, Pearson N, Sarture C, McCubbin I, Roberts D, Bradley E, Steele D, Ryan T, Dominguez R (2010) A method for quantitative mapping of thick oil spills using imaging spectroscopy: U.S. Geological Survey Open-File Report 2010-1167, p 51

Cloutis EA, Hawthorne FC, Mertzman SA, Krenn K, Cairg MA, Marcino D, Methot M, Strong J, Mustard JF, Blaney DL, Bell JF III, Vilas F (2006) Detection and discrimination of sulfate minerals using reflectance spectroscopy. Icarus 184:121-157

Cocks T, Jenssen R, Stewart A, Wilson I, Shields T (1998) The Hymap Airborne hyperspectral sensor: the system, Calibration and performance. In: Proceedings of 1st EARSEL workshop on imaging spectroscopy, Zurich, Switzerland, October 1998. EARSEL, pp 37-42

Conley S, Franco G, Faloona I, Blake DR, Peischl J, Ryerson TB (2016) Methane emissions from the 2015 Aliso Canyon blowout in Los Angeles, CA. Science 351(6279):1317-1320

Crowley JK, Williams DE, Hammarstrom JM, Piatak N, Chou I-M, Mars JC (2003) Spectral reflectance properties $(0.4-2.5 \mu \mathrm{m})$ of secondary Fe-oxide, Fe-hydroxide, and Fe-sulphate-hydrate minerals associated with sulphide-bearing mine waste. Geochem Explor Environ Anal 3:219-228

CSES (1997) ATmosphere REMoval Program (ATREM) User's Guide Version 3.0 July 1997. University of Colorado, Boulder, Colorado

Davies G, Calvin W (2017) Mapping acidic mine waste with seasonal airborne hyperspectral imagery at varying spatial scales. Environ Earth Sci 76:1-14. https://doi.org/10.1007/s12665-017-6763-X

Dennison PE, Thorpe AK, Pardyjak ER, Roberts DA, Qi Y, Green RO, Bradley ES, Funk CC (2013) High spatial resolution mapping of elevated atmospheric carbon dioxide using airborne imaging spectroscopy: radiative transfer modeling and power plant plume detection. Remote Sens Environ 139(2013):116-129

Deschamps A, Marion R, Foucher P-Y, Briottet X (2012) Estimation of aerosol type from airborne hyperspectral data: a new technique designed for industrial plume characterization. In: Proceedings of SPIE, 8534. Edinburgh

Deschamps A, Marion R, Briottet X, Foucher P-Y (2013) Simultaneous retrieval of $\mathrm{CO}_{2}$ and aerosols in a plume from hyperspectral imagery: application to the characterization of forest fire smoke using AVIRIS data. Int J Remote Sens 34(19):6837-6864. https://doi.org/10.1080/01431161.2013.80949 9

Duckworth J (2004) Mathematical data processing. In: Roberts CA, Workman J, Reeves JB III (eds) Near-infrared reflectance spectroscopy, Agronomy Monograph, vol 44. American Society of Agronomy, Madison, pp 115-132

Dufrechou G, Hohmann A, Bourguignon A, Grandjean G (2016) Targeting and mapping expansive soils (Loiret, France): geometrical analysis of laboratory soil spectra in the short-wave infrared domain (1100-2500 nm). Bull Soc Géol France 187(3):169-181

Duren R, Thorpe A, Sanders A (2017) Carlifornia baseline methane survey. Interim phase 1 report. Jet Propulsion Laboratory, California

Emmons SF, Irving JD, Loughlin GF (1927) Geology and ore deposits of the Leadville Mining District, Colorado. U.S. Geological Survey professional paper 148 
Farmer VC (1974) The infrared spectra of minerals. Mineralogical Society, London, p 539

Farrand WH (1997) Identification and mapping of ferric oxide and oxyhydroxide minerals in imaging spectrometer data of Summitville, Colorado, U.S.A., and the surrounding San Juan Mountains. Int J Remote Sens 18:1543-1552

Farrand WH, Harsanyi JC (1997) Mapping the distribution of mine tailings in the Coeur d=Alene River Valley, Idaho, through the use of a constrained energy minimization technique. Remote Sens Environ 59:64-76

Fenstermaker LK, Miller JR (1994) Identification of fluvially redistributed mill tailings using high spectral resolution aircraft data. Photogramm Eng Remote Sens 60:989-995

Filella I, Peñuelas J (1994) The red edge position and shape as indicators of plant chlorophyll content, biomass and hydric status Int. J Remote Sens 15(7):1459-1470

Franke J, Roberts DA, Halligan K, Menz G (2009) Hierarchical multiple endmember spectral mixture analysis (MESMA) of hyperspectral imagery for urban environments. Remote Sens Environ 113:1712-1723. https://doi.org/10.1016/j.rse.2009.03.018

Frankenberg C, Thorpe AK, Hook SJ, Green RO, Thompson DR, Kort EA, Hulley GC, Vance N, Bue BD, Aubrey AD (2015) The 4-Corners methane hotspot: mapping CH4 plumes at $60 \mathrm{~km}$ through $1 \mathrm{~m}$ resolution using space-and airborne spectrometers. In: AGU fall meeting abstracts

Frankenberg C, Thorpe AK, Thompson DR, Hulley G, Kort EA, Vance N, Borchardt J et al (2016) Airborne methane remote measurements reveal heavy-tail flux distribution in Four Corners region. In: Proceedings of the national academy of sciences: 201605617

Frassy F, Candiani G, Rusmini M, Maianti P, Marchesi A, Rota Nodari F, Dalla Via G, Albonico C, Gianinetto M (2014) Mapping asbestos-cement roofing with hyperspectral remote sensing over a large mountain region of the Italian Western Alps. Sensors 14:15900-15913

Frouin R, Deschamps A, Lecomte P (1990) Determination from space of atmospheric total water vapor amounts by differential absorption near $940 \mathrm{~nm}$ : theory and airborne verification. J Appl Meteorol 29:448-460

Funk CC, Theiler J, Roberts DA, Borel CC (2001) Clustering to improve matched filter detection of weak gas plumes in hyperspectral thermal imagery. IEEE Trans Geosci Remote Sens 39(7):1410-1420

Gao B-C, Goetz AFH (1990) Column atmospheric water vapor and vegetation liquid water retrievals from airborne imaging spectrometer data. J Geophys Res 95(D4):3549-3564

García-Haro FJ, Sommer S, Kemper T (2005) A new tool for variable multiple endmember spectral mixture analysis (VMESMA). Int J Remote Sens 26:2135-2162. https://doi.org/10.1080/014311605123313 37817

Gerilowski K, Tretner A, Krings T, Buchwitz M, Bertagnolio PP, Belemezov F, Erzinger J, Burrows JP, Bovensmann H (2011) MAMAP-a new spectrometer system for column-averaged methane and carbon dioxide observations from aircraft: instrument description and performance analysis. Atmos Meas Tech 4(2):215

Goetz AFH (2009) Three decades of hyperspectral remote sensing of the earth: a personal view. Remote Sens Environ 113:S5-S16. https://doi.org/10.1016/j.rse.2007.12.014

Gottwald M, Bovensmann H, Lichtenberg G, Noël S, von Bargen A, Slijkhuis S, Piters A, Hoogeveen R, von Savigny C, Buchwitz M, Kokhanovsky A, Richter A, Rozanov A, Holzer-Popp T, Bramstedt K, Lambert J-C, Skupin J, Wittrock F, Schrijver H, Burrows JP (2006) SCIAMACHY, monitoring the changing earth's atmosphere. DLR, Institut für Methodik der Fernerkundung (IMF), Weßling

Goudie A, Middleton NJ (2006) Desert dust in the global system. Springer, Berlin

Green RO (2018) Global VSWIR imaging spectroscopy and the 2017 decadal survey. In: IGARSS 20182018 IEEE international geoscience and remote sensing symposium, Valencia, pp 183-185. https:// doi.org/10.1109/igarss.2018.8518744

Guanter L, Kaufmann H, Segl K, Foerster S, Rogass C, Chabrillat S, Kuester T, Hollstein A, Rossner G, Chlebek C, Straif C, Fischer S, Schrader S, Storch T, Heiden U, Mueller A, Bachmann M, Mühle H, Müller R, Habermeyer M, Ohndorf A, Hill J, Buddenbaum H, Hostert P, van der Linden S, Leitão PJ, Rabe A, Doerffer R, Krasemann H, Xi H, Mauser W, Hank T, Locherer M, Rast M, Staenz K, Sang B (2015) The environmental mapping and analysis program (EnMAP) spaceborne imaging spectroscopy mission for. Earth Obs Remote Sens 7:8830-8857. https://doi.org/10.3390/rs70708830

Haaland DM, Thomas EV (1988) Partial least-squares methods for spectral analyses. 1. Relation to other quantitative calibration methods and the extraction of qualitative information. Anal Chem 60:1193-1200

Hamlin L, Green RO, Mouroulis P, Eastwood M, Wilson D, Dudik M, Paine C (2011) Imaging spectrometer science measurements for terrestrial ecology: AVIRIS and new developments. In: 2011 Aerospace conference, pp 1-7 
Hammarstrom JM, Seal RR II, Meier AL, Kornfeld JM (2005) Secondary sulfate minerals associated with acid drainage in the eastern US: recycling of metals and acidity in surficial environments. Chem Geol 215:407-431

Harries J (1997) Acid mine drainage in Australia: its extent and potential future liability. Kingston, ACT: Supervising Scientist

Hong Y, Adler R, Huffman G (2007) Use of satellite remote sensing data in the mapping of global landslide susceptibility. Nat Hazards 43:245-256. https://doi.org/10.1007/s11069-006-9104-Z

Hopkins FM, Ehleringer JR, Bush SE, Duren RM, Miller CE, Lai C-T, Hsu Y-K, Carranza V, Randerson JT (2016) Mitigation of methane emissions in cities: how new measurements and partnerships can contribute to emissions reduction strategies. Earth's Future 4(9):408-425

Hulley GC, Duren RM, Hopkins FM, Hook SJ, Johnson WR, Eng BT, Mihaly JM et al (2016) High spatial resolution imaging of methane and other trace gases with the airborne hyperspectral thermal emission spectrometer (HyTES). Atmos Meas Tech 9(5):2393

Hunt GR (1977) Spectral signatures of particulate minerals, in the visible and near-infrared. Geophysics 42:501-513

Hunt GR (1980) Spectroscopic properties of rocks and minerals. In: Carmichael RS (ed) Handbook of physical properties of rocks. CRC Press, Boca Raton

Hunt GR, Ashley RP (1979) Spectra of altered rocks in the visible and near infrared. Econ Geol 74:1613-1629

International Agency for Research on Cancer (2012) Arsenic, metals, fibres and dusts. In: A review of human carcinogens. International Agency for Research on Cancer Monographs on the Evaluation of Carcinogenic Risks to Humans, vol 100 C. International Agency for Research on Cancer, Lyon, France

Jha MK (2010) Natural and anthropogenic disasters: an overview. In: Jha MK (ed) Natural and anthropogenic disasters: vulnerability, preparedness and mitigation. Springer, Dordrecht, pp 1-16. https://doi. org/10.1007/978-90-481-2498-5_1

Jickells TD, An ZS, Andersen KK, Baker AR, Bergametti G, Brooks N, Cao JJ, Boyd PW, Duce RA, Hunter KA, Kawahata H, Kubilay N, laRoche J, Liss PS, Mahowald N, Prospero JM, Ridgwell AJ, Tegen I, Torres R (2005) Global iron connections between desert dust. Ocean Biogeochem Clim Sci 308:6771. https://doi.org/10.1126/science.1105959

Jones L, Jefferson I (2012) Expansive soils. In: Burland J (ed) ICE manual of geotechnical engineering. Geotechnical engineering principles, problematic soils and site investigation, vol 1. ICE Publishing, pp 413-441

Joyce KE, Belliss SE, Samsonov SV, McNeill SJ, Glassey PJ (2009) A review of the status of satellite remote sensing and image processing techniques for mapping natural hazards and disasters. Prog Phys Geogr 33:183-207. https://doi.org/10.1177/0309133309339563

Kariuki PC, Woldai T, van der Meer F (2004) Effectiveness of spectroscopy in identification of swelling indicator clay minerals. Int J Remote Sens 25:455-469

Kaufman YJ, Gao B-C (1992) Remote sensing of water vapor in the near IR from EOS/MODIS. IEEE Trans Geosci Remote Sens 30(5):871-884

Kemper T, Sommer S (2004) Use of airborne hyperspectral data to estimate residual heavy metal contamination and acidification potential in the Guadiamar floodplain Andalusia, Spain after the Aznacollar mining accident. In: Proceedings of the SPIE 5574, remote sensing for environmental monitoring, GIS applications, and geology IV, pp 224

Khanna S, Santos MJ, Ustin SL, Koltunov A, Kokaly RF, Roberts DA (2013) Detection of salt marsh vegetation stress and recovery after the Deepwater Horizon oil spill in Barataria Bay, Gulf of Mexico using AVIRIS data. PLoS ONE 8(11):e78989. https://doi.org/10.1371/journal.pone.0078989

King TVV, Clark RN, Ager C, Swayze GA (1995). In: Posey HH, Pendelton JA, Van Zyl D (eds) Proceedings: summitville forum $=95$. Colorado Geological Survey Special Publication 38, pp 59-63

Kokaly RF (2011) PRISM: processing routines in IDL for spectroscopic measurements (installation manual and user's guide, version 1.0). U.S. Geological Survey Open-File Report 2011-1155. https://pubs. usgs.gov/of/2011/1155/

Kokaly RF, Couvillion BR, Holloway JM, Roberts DA, Ustin SL, Peterson SH, Khanna S, Piazza SC (2013) Spectroscopic remote sensing of the distribution and persistence of oil from the Deepwater Horizon spill in Barataria Bay marshes. Remote Sens Environ 129:210-230. https://doi.org/10.1016/j. rse.2012.10.028

Kokaly RF, Clark RN, Swayze GA, Livo KE, Hoefen TM, Pearson NC, Wise RA, Benzel WM, Lowers HA, Driscoll RL, Klein AJ (2017) USGS spectral library version 7. U.S. Geological Survey Data Series 1035. https://doi.org/10.3133/ds 1035 
Kopačková V (2014) Using multiple spectral feature analysis for quantitative pH mapping in a mining environment. Int J Appl Earth Obs Geoinf 28:28-42. https://doi.org/10.1016/j.jag.2013.10.008

Krautwurst S, Gerilowski K, Jonsson HH, Thompson DR, Kolyer RW, Thorpe AK, Horstjann M, Eastwood M, Leifer I, Vigil S, Krings T, Borchardt J, Buchwitz M, Fladeland MM, Burrows JP, Bovensmann H (2017) Methane emissions from a Californian landfill, determined from airborne remote sensing and in situ measurements. Atmos Meas Tech 10:3429-3452

Kruckeberg AR (1984) California serpentines: flora, vegetation, geology, soils, and management problems. University of California Press, Los Angeles

Kruse FA, Dwyer JL (1993) The effects of AVIRIS atmospheric calibration methodology on identification and quantitative mapping of surface mineralogy, Drum Mtns., Utah Summaries of the Fourth JPL Airborne Geoscience Workshop JPL Publication, vol 1. Pasadena, California, pp 93-26

Kruse FA, Hauff P, Dietz J, Brock JC, Hampton L (1989) Final report contract no. 412.DEN.63786.FM (CH2 M HILL). Center for the Study of Earth from Space, University of Colorado, Boulder

Labson VF, Clark RN, Swayze GA, Hoefen TM, Kokaly R, Livo KE, Powers MH, Plumlee GS, Meeker GP (2010) Estimated lower bound for leak rates from the Deepwater Horizon spill-Interim report to the Flow Rate Technical Group from the Mass Balance Team. U.S. Geological Survey Open-File Report 2010-1132. http://pubs.usgs.gov/of/2010/1132/

Lammoglia T, Souza Filho CR (2011) Spectroscopic characterization of oils yielded from Brazilian offshore basins: potential applications of remote sensing. Remote Sens Environ 115:2525-2535

Lammoglia T, Souza Filho CR (2012) Mapping and characterization of the API gravity of offshore hydrocarbon seepages using multispectral ASTER data. Remote Sens Environ 123:381-389

Lee CM, Cable ML, Hook SJ, Green RO, Ustin SL, Mandl DJ, Middleton EM (2015) An introduction to the NASA Hyperspectral InfraRed Imager (HyspIRI) mission and preparatory activities. Remote Sens Environ 167:6-19. https://doi.org/10.1016/j.rse.2015.06.012

Lehr B, Sky B, Possolo A et al (2010) Oil budget calculator deepwater horizon: a report to the National Incident Command. NOAA

Leifer I, Lehr WJ, Simecek-Beatty D, Bradley E, Clark R, Dennison P, Hu Y, Matheson S, Jones CE, Holt B, Reif M, Roberts DA, Svejkovsky J, Swayze G, Wozencraft J (2012) State of the art satellite and airborne marine oil spill remote sensing: application to the BP Deepwater Horizon oil spill. Remote Sens Environ 124:185-209

Lentile LB, Holden ZA, Smith AMS, Falkowski MJ, Hudak AT, Morgan P, Lewis SA, Gessler PE, Benson NC (2006) Remote sensing techniques to assess active fire characteristics and post-fire effects. Int J Wildland Fire 15:319-345. https://doi.org/10.1071/WF05097

Loizzo R, Guarini R, Longo F, Scopa T, Formaro R, Facchinetti C, Varacalli G (2018) Prisma: the Italian hyperspectral mission. IGARSS 2018-2018 IEEE international geoscience and remote sensing symposium, Valencia, pp 175-178. https://doi.org/10.1109/igarss.2018.8518512

Lopez-Pamo E, Barettino D, Anton-Pacheco C, Ortiz G, Arranz JC, Gumiel JC, Martinez-Pledel B, Aparico M, Montouto O (1999) The extent of the Aznalcollar pyretic sludge spill and its effects on soils. Sci Total Environ 242:57-88

Manolakis DG, Lockwood R, Cooley T, Jacobson J (2009) Is there a best hyperspectral detection algorithm. In: Proceedings of the SPIE 7334, p. 733402, https://doi.org/10.1117/12.816917. c@ 2009 SPIE

Manolakis D, Truslow E, Pieper M, Cooley T, Brueggeman M (2014) Detection algorithms in hyperspectral imaging systems: an overview of practical algorithms. IEEE Signal Proc Mag 31:24-33

Marino CM, Panigada C, Busetto L, Galli A (2000) Environmental applications of airborne hyperspectral remote sensing: asbestos concrete sheeting identification and mapping. In: Proceedings of the fourteenth international conference: applied geologic remote sensing, Las Vagas, November 6-8th. Veridian ERIM International, pp 607-609

Marion R, Michel R, Faye C (2004) Measuring trace gases in plumes from hyperspectral remotely sensed data. IEEE Trans Geosci Remote Sens 42(4):854-864

Marion R, Michel R, Faye C (2006) Atmospheric correction of hyperspectral data over dark surfaces via simulated annealing. IEEE Trans Geosci Remote Sens 44(6):1566-1574

Massarelli C, Matarrese R, Uricchio VF, Muolo MR, Laterza M, Ernesto L (2017) Detection of asbestoscontaining materials in agro-ecosystem by the use of airborne hyperspectral CASI-1500 sensor including the limited use of two UAVs equipped with RGB cameras. Int J Remote Sens 38:2135-2149

Matsunaga T, Iwasaki A, Tsuchida S, Iwao K, Tanii J, Nakamura R, Yamamoto H, Kato S, Obata K, Kashimura O, Tanii J, Mouri K and Tachikawa T (2018) HISUI status toward FY2019 launch. In: IGARSS 2018-2018 IEEE international geoscience and remote sensing symposium, Valencia, pp 160-163. https://doi.org/10.1109/igarss.2018.8518639

Metternicht GI, Zinck JA (2003) Remote sensing of soil salinity: potentials and constraints. Remote Sens Environ 85:1-20. https://doi.org/10.1016/S0034-4257(02)00188-8 
Michel J, Owens EH, Zengel S, Graham A, Nixon Z, Allard T, Holton W, Reimer PD, Lamarche A, White M, Rutherford N, Childs C, Mauseth G, Challenger G, Taylor E (2013) Extent and degree of shoreline oiling: deepwater horizon oil spill, gulf of Mexico, USA. PLOS ONE 8:e65087

Nieke J, Rast M (2018) Towards the copernicus hyperspectral imaging mission for the environment (CHIME). In: IGARSS 2018-2018 IEEE international geoscience and remote sensing symposium, 22-27 July 2018. pp 157-159. https://doi.org/10.1109/igarss.2018.8518384

OECD (2016) The economic consequences of outdoor air pollution. OECD Publishing, Paris

Ong CCH (2013) Mapping and monitoring the environmental impacts of mining using hyperspectral data. Curtin University of Technology, Bentley

Ong CCH, Cudahy TJ (2014) Mapping contaminated soils: using remotely-sensed hyperspectral data to predict pH. Eur J Soil Sci 65:897-906. https://doi.org/10.1111/ejss.12160

Ong C, Swayze G, Clark R (2003a) An investigation of the Tetracorder expert system for multi-temporal mapping of acid drainage-related minerals using airborne hyperspectral data. In: Proceedings of the 3rd EARSel workshop on imaging spectroscopy, Herrsching, Germany, 13-16 May 2003, pp 357-362

Ong CCH, Cudahy TJ, Caccetta MS, Piggott MS (2003b) Deriving quantitative dust measurements related to iron ore handling from airborne hyperspectral data. Min Technol 112:A158-A163

Ong C, Cudahy TJ, Swayze G (2003c) Predicting acid drainage related physicochemical measurements using hyperspectral data. In: Proceedings of the 3rd EARSeL workshop on imaging spectroscopy, Herrsching, Germany, 13-16 May 2003, pp 363-373

Ong C, Lau I, Hewson R, Tongway D, Eisele A (2008) MERIWA project M385: the development of a hyperspectral environmental measurement tool for monitoring mining related infrastructure and rehabilitation: CSIRO exploration and mining report no. 271, p 122

Pan XL, Day HW, Wang W, Beckett LA, Schenker MB (2005) Residential proximity to naturally occurring asbestos and mesothelioma risk in California. Am J Respir Crit Care Med 172:1019-1025

Pascucci S, Belviso C, Cavalli RM, Palombo A, Pignatti S, Santini F (2012) Using imaging spectroscopy to map red mud dust waste: the Podgorica aluminum complex case study. Remote Sens Environ 123:139-154. https://doi.org/10.1016/j.rse.2012.03.017

Pearlman J, Carman S, Segal C, Jarecke P, Clancy P, Browne W (2001) Overview of the hyperion imaging spectrometer for the NASA EO-1 mission. In: IGARSS 2001. scanning the present and resolving the future. Proceedings. IEEE 2001 international geoscience and remote sensing symposium (Cat. No.01CH37217), 2001 2001, vol 3037. pp 3036-3038. https://doi.org/10.1109/igarss.2001.978246

Pearson RM, Swayze GA, Wiltshire R, Serina D, Clark RN (1997) Using AVIRIS imagery mineral mapping for identification of acid rock drainage sources at the California Gulch NPL Site and fluvial tailings deposits on the Arkansas River, Leadville, Colorado, USA. In: Proceedings of the 3rd international airborne remote sensing conference, Copenhagen, Denmark, pp I-102-I-109

Peters DC, Hauff PL, Livo KE (1995) Remote sensing for mine waste discrimination and characterization. In: Curran PJ, Roberston YC (eds) Proceedings of RSS 95: remote sensing in action, September 11-14, 1995, Southhampton. The Remote Sensing Society, pp 866-877

Peterson SH, Roberts DA, Beland M, Kokaly RF, Ustin SL (2015) Oil detection in the coastal marshes of Louisiana using MESMA applied to band subsets of AVIRIS data. Remote Sens Environ 159:222231. https://doi.org/10.1016/j.rse.2014.12.009

Plumlee GS, Smith KS, Montour MR, Ficklin WH, Mosier EL (1999) Geologic controls on the composition of mine waters and natural waters draining diverse mineral-deposit types. In: Filipek LH, Plumlee GS (eds) Reviews in economic geology, part B: case studies and research topics. Society of Economic Geologists, 6B, Littleton, pp 373-432

Popp C, Brunner D, Damm A, Van Roozendael M, Fayt C, Buchmann B (2012) High-resolution $\mathrm{NO}_{2}$ remote sensing from the Airborne Prism EXperiment (APEX) imaging spectrometer. Atmos Meas Tech 5:2211-2225

Qu Z, Kindel BC, Goetz AFH (2003) The high accuracy atmospheric correction for hyperspectral data (HATCH) model. IEEE Trans Geosci Remote Sens 41(6):1223-1231

RadCalNet (2018) Radiometric Calibration Network. https://www.radcalnet.org/\#!/. Accessed 2 Feb 2019

Richter R, Schläpfer D (2002) Geo-atmospheric processing of airborne imaging spectrometry data: part 2. Atmospheric/topo-graphic correction. Int J Remote Sens 23:2631-2649

Roberts DA, Bradley ES, Cheung R, Leifer I, Dennison PE, Margolis JS (2010) Mapping methane emissions from a marine geological seep source using imaging spectrometry. Remote Sens Environ 114(3):592-606

Rockwell BW, McDougal RR, Gent CA (2005) Remote sensing for environmental site screening and watershed evaluation in Utah mine lands-East Tintic Mountains, Oquirrh Mountains, and Tushar Mountains. U.S. Geological Survey Scientific Investigations Report 2004-5241 
Rodger A (2011) SODA: a new method of in-scene atmospheric water vapor estimation and post-flight spectral recalibration for hyperspectral sensors application to the HyMap sensor at two locations. Remote Sens Environ 115(2):536-547

Rodgers CD (2000) Inverse methods for atmospheric sounding: theory and practice, vol 2. World Scientific, New York

Rogge DM, Rivard B, Zhang J, Feng J (2006) Iterative spectral unmixing for opti-mizing per-pixel endmember sets. IEEE Trans Geosci Remote Sens 44(12):3725-3736

Ross M (1999) The health effects of mineral dusts. In: Plumlee GS, Logsdon MJ (eds) Reviews in economic geology, part a: the environmental geochemistry of mineral deposits: processes, techniques, and health issues, 6A. Society of Economic Geologists, Littleton, pp 339-356

Salomonson VV, Barnes WL, Maymon PW, Montgomery HE, Ostrow H (1989) MODIS: advanced facility instrument for studies of the Earth as a system. IEEE Trans Geosci Remote Sens 27:145-153. https:// doi.org/10.1109/36.20292

Scafutto RDM, Souza Filho CR (2016) Quantitative characterization of crude oils and fuels in mineral substrates using reflectance spectroscopy: implications for remote sensing. Int J Appl Earth Obs Geoinf 50:221-242

Scafutto RDM, Souza Filho CR, Rivard B (2016) Characterization of mineral substrates impregnated with crude oils using proximal infrared hyperspectral imaging. Remote Sens Environ 179:116-130

Scafutto RDM, Souza Filho CR, de Oliveira WJ (2017) Hyperspectral remote sensing detection of petroleum hydrocarbons in mixtures with mineral substrates: implications for onshore exploration and monitoring. ISPRS J Photogramm Remote Sens 128:146-157

Schaepman ME, Ustin SL, Plaza AJ, Painter TH, Verrelst J, Liang S (2009) Earth system science related imaging spectroscopy—an assessment. Remote Sens Environ 113:S123-S137

Schläpfer D, Borel CC, Keller J, Itten KI (1998) Atmospheric pre-corrected differential absorption technique to retrieve columnar water vapor. Remote Sens Environ 65:353-366

Shaw SC, Groat LA, Jambor JL, Blowes DW, Hanton-Fong CJ, Stuparyk RA (1998) Mineralogical study of base metal tailings with various sulfide contents, oxidized in laboratory columns and field lysimeters. Environ Geol 33(2/3):209-217

Shi X-Z, Lau IC, Aspandiar M (2014a) Comparison of PLSR modelling and indicative mineral mapping of airborne hyperspectral imagery for acid sulphate soil assessment. AU Int J Remote Sens 35:13091330. https://doi.org/10.1080/01431161.2013.876121

Shi X, Aspandiar M, Lau IC, Oldmeadow D (2014b) Assessment of acid sulphate soil both on surface and in subsurface using hyperspectral data. Can J Remote Sens 39(6):468-480

Spinetti C, Carrère V, Buongiorno MF, Sutton AJ, Tamar Elias T (2008) Carbon dioxide of PuuOo volcanic plume at Kilauea retrieved by AVIRIS hyperspectral data. Remote Sens Environ 112(6):3192-3199

Stocker AD, Reed IS, Yu X-L (1990) Multidimensional signal processing for electro-optical target detection. In: Proceedings of the SPIE 1305, signal and data processing of small targets 1990, 218 (October 1, 1990). https://doi.org/10.1117/12.21593

Sunshine JM, Pieters CM, Pratt SF (1990) Deconvolution of mineral absorption bands: an improved approach. J Geophys Res 95:6955-6966. https://doi.org/10.1029/jb095ib05p06955

Swayze GA, Kokaly RF (2016) Detection of potentially asbestos-bearing rocks using imaging spectroscopy, developing integrated methods to address complex resource and environmental issues. In: Smith KS, Phillips JD, McCafferty AE, Clark RN (eds) Developing integrated methods to address complex resource and environmental issues. U.S. Geological Survey Circular 1413, pp 95-100

Swayze GA, Clark RN, Pearson RM, Livo KE (1996) Mapping acid-generating minerals at the California Gulch Superfund Site in Leadville, Colorado using imaging spectroscopy. In: Summaries of the Sixth Annual JPL Airborne Earth Science Workshop, Jet Propulsion Laboratory Publication 96-4, 1, pp $231-234$

Swayze GA, Smith KS, Clark RN, Sutley SJP, Pearson RM, Vance JS, Hageman PL, Briggs PH, Meier AL, Singleton MJ, Roth S (2000) Using imaging spectroscopy to map acidic mine waste. Environ Sci Technol 34:47-54

Swayze GA, Clark RN, Goetz AFH, Chrien TG, Gorelick NS (2003) Effects of spectrometer band pass, sampling, and signal-to-noise ratio on spectral identification using the Tetracorder algorithm. J Geophys Res Planets 108:5105. https://doi.org/10.1029/2002je001975

Swayze GA, Kokaly RF, Higgins CT, Clark RN, Meeker GP, Clinkenbeard JP, Sutley SJ (2004) Using imaging spectroscopy to map ultramafic rocks, serpentinites, and tremolitic rocks in El Dorado and Plumas Counties, California. U.S. Geological Survey Open-File Report 2004-1304

Swayze GA, Kokaly RF, Higgins CT, Clinkenbeard JP, Clark RN, Lowers HA, Sutley SJ (2009) Mapping potentially asbestos-bearing rocks using imaging spectroscopy. Geology 37(8):763-766

Swinehart DF (1962) The Beer-Lambert law. J Chem Educ 39(7):333 
Thompson DR, Gao B-C, Green RO, Roberts DA, Dennison PE, Lundeen SR (2015) Atmospheric correction for global mapping spectroscopy: ATREM advances for the HyspIRI preparatory campaign. Remote Sens Environ 167:64-77

Thompson DR, Leifer I, Bovensmann H, Eastwood M, Fladeland M, Frankenberg C, Gerilowski K et al (2105) Real-time remote detection and measurement for airborne imaging spectroscopy: a case study with methane. Atmos Meas Tech 8(10):4383-4397

Thompson DR, Thorpe AK, Frankenberg C, Green RO, Duren R, Guanter L, Hollstein A, Middleton E, Ong L, Ungar S (2016) Space-based remote imaging spectroscopy of the Aliso Canyon $\mathrm{CH} 4$ super-emitter. Geophys Res Lett 43(12):6571-6578

Thompson DR, Guanter L, Berk A, Gao B-C, Richter R, Schläpfer D, Thome KJ (2019) Retrieval of atmospheric parameters and surface reflectance from visible and shortwave infrared imaging spectroscopy data. Surv Geophys. https://doi.org/10.1007/s10712-018-9488-9 (this issue)

Thorpe AK, Roberts DA, Dennison PE, Bradley ES, Funk CC (2012) Point source emissions mapping using the airborne visible/infrared imaging spectrometer (AVIRIS). In: SPIE defense, security, and sensing. International Society for Optics and Photonics, pp 839013-839013

Thorpe AK, Roberts DA, Bradley ES, Funk CC, Dennison PE, Leifer I (2013) High resolution mapping of methane emissions from marine and terrestrial sources using a cluster-tuned matched filter technique and imaging spectrometry. Remote Sens Environ 134:305-318

Thorpe AK, Frankenberg C, Aubrey AD, Roberts DA, Nottrott AA, Rahn TA, Sauer JA, Dubey MK, Costigan KR, Arata C, Steffke AM, Hills S, Haselwimmer C, Charlesworth D, Funk CC, Green RO, Lundeen SR, Boardman JW, Eastwood ML, Sarture CM, Nolte SH, Mccubbin IB, Thompson DR, McFadden JP (2016) Mapping methane concentrations from a controlled release experiment using the next generation airborne visible/infrared imaging spectrometer (AVIRIS-NG). Remote Sens Environ 179:104-115

Tralli DM, Blom RG, Zlotnicki V, Donnellan A, Evans DL (2005) Satellite remote sensing of earthquake, volcano, flood, landslide and coastal inundation hazards. ISPRS 59:185-198. https://doi. org/10.1016/j.isprsjprs.2005.02.002

United Nations Office for Disaster Risk Reduction (2017) Terminology. United Nations Office for Disaster Risk Reduction. http://www.unisdr.org/we/inform/terminology. Accessed 08 Oct 2017

van der Linden S, Rabe A, Held M, Jakimow B, Leitão P, Okujeni A, Schwieder M, Suess S, Hostert P (2015) The EnMAP-Box-a toolbox and application programming interface for EnMAP data processing. Remote Sens 7:11249

van Geen A, Chase Z (1998) Recent mine spill adds to contamination of southern Spain Eos. Trans Am Geophys Union 79:449-455. https://doi.org/10.1029/98EO00340

Van Oss CJ, Naim JO, Costanzo PM, Giese RF Jr, Wu W, Sorling AF (1999) Impact of different asbestos species and other mineral particles on pulmonary pathogenesis. Clays Clay Miner 47(6):697-707

Vane G, Green RO, Chrien TG, Enmark HT, Hansen EG, Porter WM (1993) The airborne visible/infrared imaging spectrometer (AVIRIS). Remote Sens Environ 44:127-143. https://doi. org/10.1016/0034-4257(93)90012-M

Westrich JR, Ebling AM, Landing WM, Joyner JL, Kemp KM, Griffin DW, Lipp EK (2016) Saharan dust nutrients promote Vibrio bloom formation in marine surface waters. Proc Natl Acad Sci 113:5964-5969. https://doi.org/10.1073/pnas.1518080113

Yitegasu FA, Van der Meer F, van der Werff H, Zigterman W (2009) Quantifying engineering parameters of expansive soils from their reflectance spectra. Eng Geol 105(3-4):151-160

Zabcic N, Rivard B, Ong C, Mueller A (2014) Using airborne hyperspectral data to characterize the surface $\mathrm{pH}$ and mineralogy of pyrite mine tailings. Int J Appl Earth Obs Geoinf 32:152-162. https:// doi.org/10.1016/j.jag.2014.04.008

Publisher's Note Springer Nature remains neutral with regard to jurisdictional claims in published maps and institutional affiliations. 


\section{Affiliations}

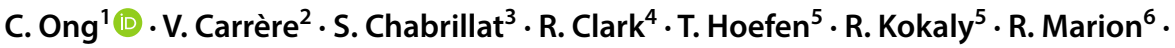
C. R. Souza Filho ${ }^{7}$. G. Swayze ${ }^{5}$ D. R. Thompson ${ }^{8}$

1 Commonwealth Scientific Industrial Research Organisation (CSIRO), 26 Dick Perry Avenue, Kensington, WA 6151, Australia

2 Faculté des Sciences et des Techniques UMR-CNRS 6112 - Laboratoire Planetologie et Geodynamique, Université de Nantes, 2 rue de la Houssinière, BP 92208, 44322 Nantes Cedex 3, France

3 German Research Centre for Geosciences (GFZ), Telegrafenberg, 14473 Potsdam, Germany

4 Planetary Science Institute, 1546 Cole Blvd \#120, Lakewood, CO 80401, USA

5 United States Geological Survey (USGS), Bld. 20 Rm C2019, Denver Federal Center, Kipling and 6th, Denver, CO 80225, USA

6 Laboratoire Télédétection, Surveillance, Environnement Commissariat à l'Energie Atomique et aux énergies alternatives Centre DAM/Ile de France, Bruyères-le-Châtel, 91297 Arpajon Cedex, France

7 Institute of Geosciences, State University of Campinas (UNICAMP), Rua Carlos Gomes, 250, Campinas, SP CEP 13083-855, Brazil

8 Jet Propulsion Laboratory, California Institute of Technology, 4800 Oak Grove Dr, Pasadena, CA 91109, USA 